\title{
Self-Structuring of Lamellar Bridged Silsesquioxanes with Long Side Spacers
}

Mariana Fernandes, ${ }^{+, \neq, \S}$ Sónia S. Nobre, ${ }^{\S, \perp, \nabla}$ Xu Qinghong, ${ }^{\S, \nabla}$ Carole Carcel, ${ }^{\S}$ Jean Nicolas Cachia, ${ }^{\S}$

Xavier Cattoën, ${ }^{\S}$ José M. Sousa, ${ }^{+, \|}$Rute A. S. Ferreira, ${ }^{\perp}$ Luís D. Carlos, ${ }^{\perp}$ Celso V. Santilli,

Michel Wong Chi Man, ${ }^{*, \S}$ and Verónica de Zea Bermudez ${ }^{*,+, \neq}$

${ }^{\dagger}$ Chemistry Departement and ${ }^{\ddagger}$ CQ-VR, University of Trás-os-Montes e Alto Douro 5001-801 Vila Real, Portugal

${ }^{\S}$ Institute Charles Gerhardt Montpellier, UMR 5253 CNRS-UM2-ENSCM-UM1 8 rue de l' école normale, 34296 Montpellier Cedex 5, France

${ }^{\perp}$ Physics Department, CICECO, University of Aveiro, 3810-193 Aveiro, Portugal

"LEPAE-Departament of Chemical Engineering, Faculty of Engineering of the University of Porto, Rua Dr. Roberto Frias, 4200-465 Porto, Portugal

"Institute of Chemistry/UNESP, CP 355, 14800-900, Araraquara-SP, Brazil

Supporting Information

ABSTRACT: Diurea cross-linked bridged silsesquioxanes (BSs) $\mathrm{C}_{10} \mathrm{C}_{n} \mathrm{C}_{10}$ derived from organosilane precursors, including decylene chains as side spacers and alkylene chains with variable length as central spacers $(\mathrm{EtO})_{3} \mathrm{Si}-$ $\left(\mathrm{CH}_{2}\right)_{10}-\mathrm{Y}-\left(\mathrm{CH}_{2}\right)_{n}-\mathrm{Y}-\left(\mathrm{CH}_{2}\right)_{10}-\mathrm{Si}(\mathrm{OEt})_{3}(n=7,9-12 ; Y=$ urea group and $\mathrm{Et}=$ ethyl), have been synthesized through the combination of self-directed assembly and an acid-catalyzed sol-gel route involving the addition of dimethylsulfoxide (DMSO) and a large excess of water. This new family of hybrids has enabled us to conclude that the length of the side spacers plays a unique role in the structuring of alkylene-based BSs, although their morphology remains unaffected. All the samples adopt a lamellar structure.

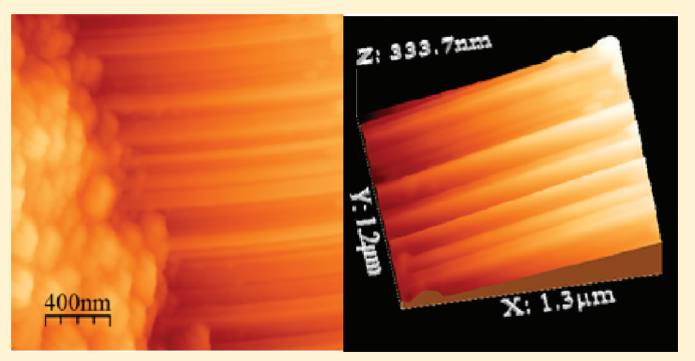
While the alkylene chains are totally disordered in the case of the $\mathrm{C}_{10} \mathrm{C}_{7} \mathrm{C}_{10}$ sample, a variable proportion of all-trans and gauche conformers exists in the materials with longer central spacers. The highest degree of structuring occurs for $n=9$. The inclusion of decylene instead of propylene chains as side spacers leads to the formation of a stronger hydrogen-bonded urea-urea array as evidenced by two dimensional correlation Fourier transform infrared spectroscopic analysis. The emission spectra and emission quantum yields of the $\mathrm{C}_{10} \mathrm{C}_{n} \mathrm{C}_{10}$ materials are similar to those reported for diurea cross-linked alkylene-based BSs incorporating propylene chains as side spacers and prepared under different experimental conditions. The emission of the $\mathrm{C}_{10} \mathrm{C}_{n} \mathrm{C}_{10}$ hybrids is ascribed to the overlap of two distinct components that occur within the urea cross-linkages and within the siliceous nanodomains. Time-resolved photoluminescence spectroscopy has provided evidence that the average distance between the siliceous domains and the urea cross-links is similar in the $\mathrm{C}_{10} \mathrm{C}_{n} \mathrm{C}_{10} \mathrm{BS}$ s and in oxyethylene-based hybrid analogues incorporating propylene chains as side spacers (diureasils), an indication that the longer side chains in the former materials adopt gauche conformations. It has also allowed us to demonstrate for the first time that the emission features of the urea-related component of the emission of alkylene-based BSs depend critically on the length of the side spacers.

\section{INTRODUCTION}

In materials science, structure and morphology are considered as key parameters that primarily dictate the features of the materials. Their control is thus of the utmost interest to tailor the properties of a single material, depending on the required application.

Bridged silsesquioxanes $(\mathrm{BSs})^{1-3}$ constitute an important family of siliceous materials in which the intimate coexistence of inorganic domains and organic fragments endow them with very interesting perspectives for applications in optics, ${ }^{4,5}$ catalysis ${ }^{6}$ or microelectronics. ${ }^{7}$ Typically, BSs are synthesized by means of the sol-gel process from bridged organosilanes. Although usually obtained as amorphous materials, BSs have also been produced in the form of periodic mesoporous organosilicas ${ }^{8}$ via the addition of external template or as nanostructured materials via self-templating effects. ${ }^{9}$
The particular case of the BSs obtained through a combination of self-directed assembly routes and sol-gel reactions offers a wide range of possibilities in terms of morphology fine-tuning. In these systems, self-directed assembly ${ }^{10}$ of silsesquioxane precursor molecules with the general formula $(\mathrm{EtO})_{3} \mathrm{Si}-\mathrm{S}_{2}-\mathrm{Y}-\mathrm{S}_{1}-$ $\mathrm{Y}-\mathrm{S}_{2}-\mathrm{Si}(\mathrm{OEt})_{3}$ (where the central spacer $\mathrm{S}_{1}$ is an alkylene chain with variable length $\left(-\left(\mathrm{CH}_{2}\right)_{n}-\right)$, an arylene, or a cyclohexylene group, the side spacers $\mathrm{S}_{2}$ are short alkylene chains $\left(-\left(\mathrm{CH}_{2}\right)_{m}-\right)$ (in general, propylene chains, $m=3$ ) and the cross-link $\mathrm{Y}$ is the urea $(-\mathrm{NHC}(=\mathrm{O}) \mathrm{NH}-)$ group $)$ is governed

Received: March 10, 2011

Revised: July 31, 2011

Published: August 02, 2011 
by the growth of a supramolecular architecture that acts as an internal structure-directing agent. ${ }^{11-17}$ The driving forces of the process are weak interactions (hydrogen bonds formed between $\mathrm{Y}$ groups and $\pi-\pi$ or hydrophobic interactions established between $S_{1}$ moieties), which yield hierarchically structured long-range ordered architectures with well-defined morphologies at the macroscopic scale.

BS hybrids exhibiting chiral helical morphology were produced from $(\mathrm{EtO})_{3} \mathrm{Si}-\mathrm{S}_{2}-\mathrm{Y}-\left(\mathrm{C}_{6} \mathrm{H}_{10}\right)-\mathrm{Y}-\mathrm{S}_{2}-\mathrm{Si}(\mathrm{OEt})_{3}$ (where $\left.\mathrm{S}_{2}=-\left(\mathrm{CH}_{2}\right)_{3}-\right) R, R$ and $S, S$ enantiopure precursors. ${ }^{18}$ Chirality transcription from the cyclohexyl-based enantiomers depends critically on the experimental conditions. Acid catalysis yielded right- or left-handed helical fibres, respectively, or a featureless granular solid from the racemic mixture. Basic catalysis led to the formation of hollow tubular or spherical silica from the enantiopure compounds or the racemic mixture, respectively. ${ }^{19,20}$ Interestingly, it was later shown that under acidic catalysis, the length of the side spacer $S_{2}$ could also play an important role in the morphology of the resulting hybrids. ${ }^{21}$ Materials incorporating propyl and butyl $\left(\mathrm{S}_{2}=-\left(\mathrm{CH}_{2}\right)_{4}-\right)$ side spacers consisted of fiberlike structures. Although chirality transcription prevailed, helicity was reversed, demonstrating an odd/even effect due to the odd or even number of carbon atoms in the $S_{2}$ chain. Platelike shapes were formed instead from the precursors containing pentylene $\left(-\left(\mathrm{CH}_{2}\right)_{5}-\right)$ and decylene $\left(-\left(\mathrm{CH}_{2}\right)_{10}-\right)$ side spacers. A lamellar structure was observed in the hybrid with the longest $\mathrm{S}_{2}$ chain. $^{21}$

The most extensively investigated ordered BS structures have been undoubtedly the lamellar packed structures synthesized from the alkylene-based precursors $(\mathrm{EtO})_{3} \mathrm{Si}-\left(\mathrm{CH}_{2}\right)_{3}-\mathrm{Y}-$ $\left(\mathrm{CH}_{2}\right)_{n}-\mathrm{Y}-\left(\mathrm{CH}_{2}\right)_{3}-\mathrm{Si}(\mathrm{OEt})_{3}(\mathbf{P n})^{10-17}$ In this class of hybrids, the synthetic procedure adopted also exerts a dramatic influence on the final morphology: hydrochloric acid $(\mathrm{HCl})$ catalyzed hydrolysis induced the formation of lamellar packing, whereas fluoride ion $\left(\mathrm{F}^{-}\right)$-catalyzed hydrolysis under stoichiometric conditions yielded amorphous materials. ${ }^{10,12}$ It was also demonstrated that the degree of order of the hybrids increases with the length of the central spacer, $S_{1}$. Chains with less than eight methylene groups led, however, to disordered materials, regardless of the reaction conditions employed. ${ }^{12,14}$

The case of the dodecylene $(n=12)$-based precursor P12 is worth mentioning in this context because it is an excellent example of easy tuning of the degree of order, dimension, and design of the final hybrid compound via judicious modification of the reaction conditions. The $\mathrm{HCl}$-catalyzed synthesis performed in a large excess of water (molar ratio $\mathrm{P12} / \mathrm{H}_{2} \mathrm{O} / \mathrm{HCl}=$ 1:600:0.2) induced the formation of a crystalline lamellar structure (L12). ${ }^{10,12-14}$ In contrast, the addition of ammonium fluoride $\left(\mathrm{NH}_{4} \mathrm{~F}\right)$, ethanol $(\mathrm{EtOH})$, and a stoichiometric amount of water (molar ratio $\mathrm{P} 12 / \mathrm{H}_{2} \mathrm{O} / \mathrm{EtOH} / \mathrm{NH}_{4} \mathrm{~F}=1: 6: 60: 0.01$ ) resulted in an amorphous material with either granular-like morphology $(A 12)^{12}$ or an irregular microsphere shape with a rough surface composed of plates. ${ }^{16}$

Recently, we reported that lanthanide ions may play a structuring role under the same reaction conditions employed to produce $\mathbf{L 1 2}$ and A12. ${ }^{15,16}$ When the synthetic procedure used to prepare $\mathbf{L} 12$ was adopted and $\mathrm{Eu}^{3+}$ ions were incorporated (introduced as europium chloride $\left(\mathrm{EuCl}_{3}\right)$ ) (molar ratio $\mathrm{P} 12 / \mathrm{H}_{2} \mathrm{O} / \mathrm{HCl} / \mathrm{EuCl}_{3}=1: 600: 0.2: x$, where $x=0.05,0.95$, and 2.9), a photoluminescent lamellar BS (Eu@L12) was formed. ${ }^{15}$ The combination of $\mathrm{NH}_{4} \mathrm{~F}$-catalyzed sol-gel reactions and $\mathrm{Eu}^{3+}$ doping yielded, instead, photoluminescent Eu@A12 hybrids, the morphology and size of which could be easily altered through the variation of the $\mathrm{Eu}^{3+}$ concentration: (1) Microfibers or twisted microbundles made of nanoplates assembled in a brick-like tileto-tile arrangement (Eu@A12-1) appeared at low $\mathrm{Eu}^{3+}$ content (molar ratio P12/ $\mathrm{H}_{2} \mathrm{O} / \mathrm{EtOH} / \mathrm{NH}_{4} \mathrm{~F} / \mathrm{EuCl}_{3}=1: 6: 60: 0.01: 0.74$ ); (2) dumbbell-like microobjects (Eu@A12-2) were formed at higher $\mathrm{Eu}^{3+}$ content (molar ratio $\mathrm{P12} / \mathrm{H}_{2} \mathrm{O} / \mathrm{EtOH} / \mathrm{NH}_{4} \mathrm{~F} / \mathrm{EuCl}_{3}=$ 1:6:60:0.01:1.42). ${ }^{16}$ The influence of the type of solvent was emphasized more recently. ${ }^{17}$ When the synthetic route employed to prepare $\mathbf{L} 12$ was combined with the incorporation of a large excess of dimethylsulfoxide (DMSO) (molar ratio P12/ $\mathrm{H}_{2} \mathrm{O} / \mathrm{DMSO} /$ $\mathrm{HCl}=1: 527: 388: 0.175)$, a material with a microsphere-like shape that mimics sea sponges was produced (L12D). ${ }^{17}$

With the goal of determining the influence of the side spacers, $S_{2}$, on the structuring, morphology, and ultimately, on the optical properties of the P12-derived materials, we have investigated in the present work a series of alkylene-based hybrid materials (henceforth designated as $\mathrm{C}_{10} \mathrm{C}_{n} \mathrm{C}_{10}$ ) derived from silsesquioxane precursors similar to P12, including side spacers, $\mathrm{S}_{2}$, composed of decylene chains instead of propylene chains $(\mathrm{EtO})_{3} \mathrm{Si}-\left(\mathrm{CH}_{2}\right)_{10}-\mathrm{Y}-\left(\mathrm{CH}_{2}\right)_{n}-\mathrm{Y}-\left(\mathrm{CH}_{2}\right)_{10}-\mathrm{Si}(\mathrm{OEt})_{3}$ with $n=7,9-12(\mathbf{P} 10-n-10)$. Because of the higher proportion of organic component, the solubility of the precursor molecules in water is lower than that of the Pn precursor molecules. This problem was overcome through the addition of a mixture of water/DMSO. The molar ratio $\mathbf{P 1 0} \boldsymbol{n} \boldsymbol{n}-\mathbf{1 0} / \mathrm{H}_{2} \mathrm{O} / \mathrm{DMSO} / \mathrm{HCl}=$ 1:527:388:0.175 employed here coincides with that previously used to prepare the spongelike L12D material. ${ }^{17,22}$

\section{EXPERIMENTAL SECTION}

Materials. The $\alpha, \omega$-diaminoalkanes were purchased from Aldrich (1,7-diaminoheptane, $\left.\mathrm{NH}_{2}-\mathrm{C}_{7}-\mathrm{NH}_{2}, 97 \%\right)$, Acros (1,9diaminononane, $\mathrm{NH}_{2}-\mathrm{C}_{9}-\mathrm{NH}_{2}, 98 \%$; and 1,10-diaminodecane, $\left.\mathrm{NH}_{2}-\mathrm{C}_{10}-\mathrm{NH}_{2}, 97 \%\right)$, ABCR (1,11-diaminoundecane, $\mathrm{NH}_{2}-$ $\left.\mathrm{C}_{11}-\mathrm{NH}_{2}, 97 \%\right)$, and Fluka (1,12-diaminododecane, $\mathrm{NH}_{2}-\mathrm{C}_{12}-$ $\mathrm{NH}_{2}, 97 \%$ ). 10-Isocyanatodecyltriethoxysilane (ICDTES) was prepared according to the procedure described elsewhere. ${ }^{23}$ Dichloromethane $\left(\mathrm{CH}_{2} \mathrm{Cl}_{2}\right)$ and pentane were dried over $\mathrm{CaH}_{2}$ and freshly distilled prior to use. DMSO $\left(\left(\mathrm{CH}_{3}\right)_{2} \mathrm{~S}=\mathrm{O}\right.$, SDS, synthesis grade), ethanol and acetone were used as received.

Synthesis of the Bridged Organosilanes. The precursors P10- $n$-10 were synthesized in Schlenk tubes under anhydrous conditions (Scheme 1) and stored under a dry atmosphere of nitrogen $\left(\mathrm{N}_{2}\right)$. In a typical experiment, ICDTES (1.96 g, 5.6 $\mathrm{mmol})$ was added to a $\mathrm{CH}_{2} \mathrm{Cl}_{2}$ solution $(60 \mathrm{~mL})$ of the diamine $(2.6 \mathrm{mmol})$ at room temperature. A precipitate formed within a few minutes. After $24 \mathrm{~h}$, the solvent was removed under vacuum, and the residue was washed with pentane $(40 \mathrm{~mL})$. After drying, the bis(urea) compound was obtained as a white wax. P10-7-10: ${ }^{1} \mathrm{H} \mathrm{NMR}\left(\mathrm{CDCl}_{3}, 400 \mathrm{MHz}\right): 0.60(\mathrm{~m}, 4 \mathrm{H}) ; 1.18-1.53(\mathrm{~m}$, $60 \mathrm{H}) ; 3.09(\mathrm{~m}, 8 \mathrm{H}) ; 3.79(\mathrm{q}, 7.0 \mathrm{~Hz}, 12 \mathrm{H}) ; 5.50(\mathrm{br}, 4 \mathrm{H}) .{ }^{13} \mathrm{C}$ NMR $\left(\mathrm{CDCl}_{3}, 100 \mathrm{MHz}\right): 10.4 ; 18.3 ; 22.8 ; 26.4 ; 27.1 ; 28.6$; $29.3 ; 29.48 ; 29.53 ; 29.7 ; 30.1 ; 30.5 ; 33.2 ; 40.0 ; 40.4 ; 58.3 ; 159.3$. P10-9-10: ${ }^{1} \mathrm{H}$ NMR $\left(\mathrm{CDCl}_{3}, 400 \mathrm{MHz}\right)$ : $0.62(\mathrm{~m}, 4 \mathrm{H})$; $1.20-1.53(\mathrm{~m}, 64 \mathrm{H}) ; 3.14(\mathrm{~m}, 8 \mathrm{H}) ; 3.81$ (q, $7.0 \mathrm{~Hz}, 12 \mathrm{H})$; 4.74 (br, 4H). ${ }^{13} \mathrm{C} \mathrm{NMR}\left(\mathrm{CDCl}_{3}, 100 \mathrm{MHz}\right): 10.4 ; 18.3 ; 22.8$; $26.4 ; 27.0 ; 28.6 ; 28.9 ; 29.2 ; 29.4 ; 29.5 ; 29.6 ; 30.0 ; 30.3 ; 33.2$; 40.2; 40.5; 58.3; 158.7. P10-10-10: ${ }^{1} \mathrm{H}$ NMR $\left(\mathrm{CDCl}_{3}, 400\right.$ $\mathrm{MHz}): 0.62(\mathrm{~m}, 4 \mathrm{H}) ; 1.18-1.34(\mathrm{~m}, 66 \mathrm{H}) ; 3.14(\mathrm{~m}, 8 \mathrm{H})$; 3.81 (q, $7.0 \mathrm{~Hz}, 12 \mathrm{H}) ; 4,52(\mathrm{br}, 4 \mathrm{H}) .{ }^{13} \mathrm{C} \mathrm{NMR}\left(\mathrm{CDCl}_{3}\right.$, 
Scheme 1. Synthetic Scheme of the Reaction

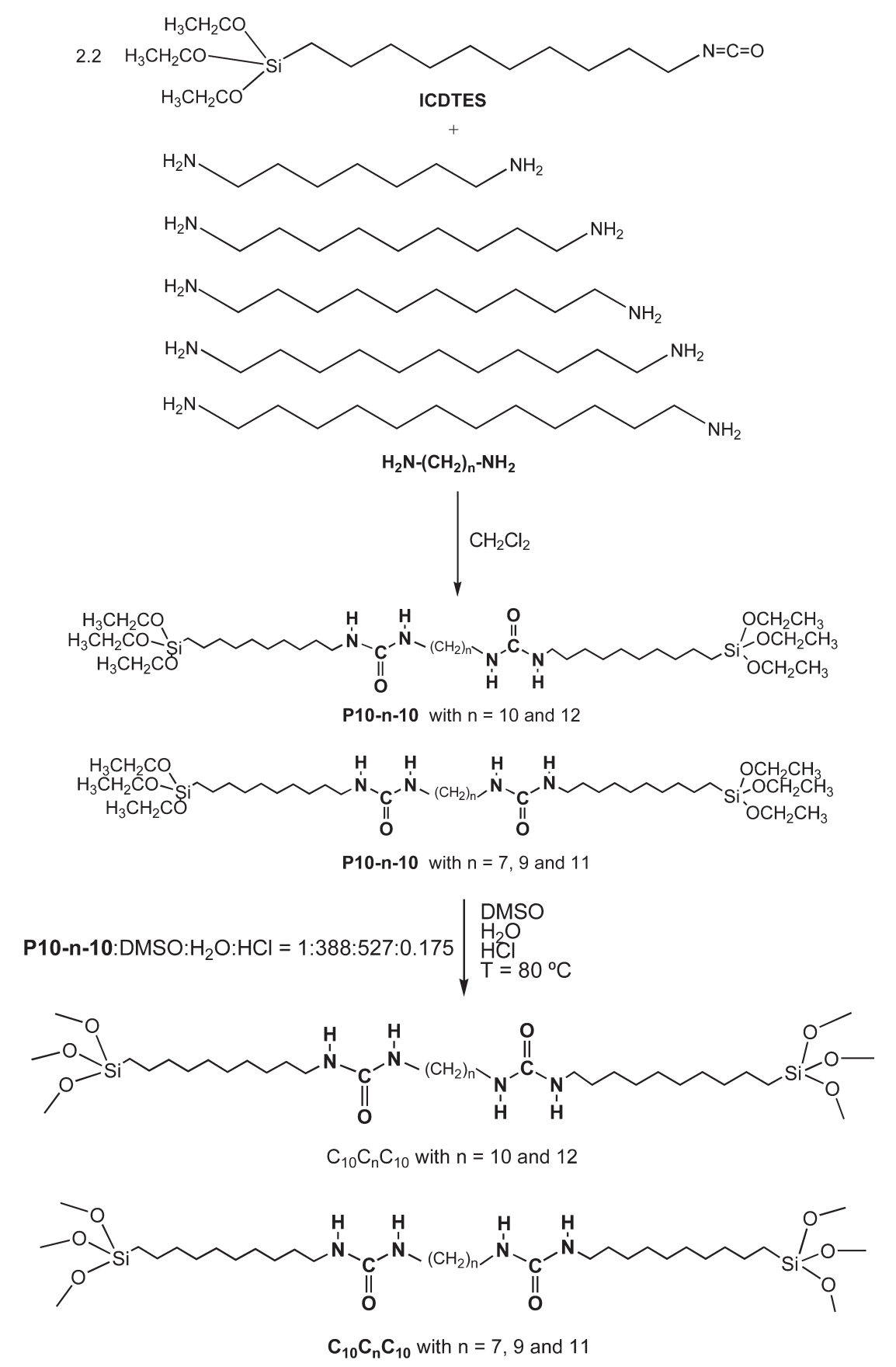

$100 \mathrm{MHz}): 10.4 ; 18.3 ; 22.8 ; 26.6 ; 26.9 ; 28.9 ; 29.0 ; 29.2 ; 29.4$; 29.5; 29.6; 30.1; 30.3; 33.2; 40.5; 40.6; 58.3; 158.5. P10-11-10: ${ }^{1} \mathrm{H} \mathrm{NMR}\left(\mathrm{CDCl}_{3}, 400 \mathrm{MHz}\right): 0.61(\mathrm{~m}, 4 \mathrm{H}) ; 1.15-1.51(\mathrm{~m}$, $68 \mathrm{H}) ; 3.11(\mathrm{~m}, 8 \mathrm{H}) ; 3.80(\mathrm{q}, 7.0 \mathrm{~Hz}, 12 \mathrm{H}) ; 5.04(\mathrm{br}, 4 \mathrm{H}) .{ }^{13} \mathrm{C}$ NMR $\left(\mathrm{CDCl}_{3}, 100 \mathrm{MHz}\right): 10.4 ; 18.3 ; 22.8 ; 26.7 ; 27.0 ; 29.1$; 29.2 ; 29.3 (2C); 29.46; 29.52; 29.6; 30.3; 30.4; 33.2; 40.3; 40.4; 58.3; 158.9. P10-12-10: ${ }^{1} \mathrm{H}$ NMR $\left(\mathrm{CDCl}_{3}, 400 \mathrm{MHz}\right): 0.61(\mathrm{~m}$, $4 \mathrm{H}) ; 1.18-1.53(\mathrm{~m}, 70 \mathrm{H}) ; 3.14(\mathrm{~m}, 8 \mathrm{H}) ; 3.81$ (q, $7.0 \mathrm{~Hz}, 12 \mathrm{H})$; 4.37 (br, $4 \mathrm{H}) .{ }^{13} \mathrm{C} \mathrm{NMR}\left(\mathrm{CDCl}_{3}, 100 \mathrm{MHz}\right): 10.4 ; 18.3 ; 22.8$; 26.7 ; $26.9 ; 29.1 ; 29.18 ; 29.23$ (2C); $29.4 ; 29.5 ; 29.6$; 30.2; 30.3; $33.2 ; 40.6 ; 40.7 ; 58.3 ; 158.3$.

Synthesis of the BSs. In a typical experiment, a mass of P10- $n-10(1.2 \mathrm{mmol})$ was heated in DMSO $(33 \mathrm{~mL}, 464 \mathrm{mmol})$ until the solution got clear. While cooling to room temperature, the mixture gelified. After addition of water $(9.3 \mathrm{~mL}, 517 \mathrm{mmol})$, the mixture was warmed up to $80{ }^{\circ} \mathrm{C}$. To the resulting cloudy solution, a solution of $\mathrm{HCl}\left(0.1 \mathrm{~N}, 2.1 \mathrm{~mL}, 0.21 \mathrm{mmol}_{\mathrm{HCl}}\right.$ and 117 $\left.\mathrm{mmol}_{\mathrm{H} 2 \mathrm{O}}\right)$ was added. The molar ratio of P10- $n-10 / \mathrm{DMSO} /$ $\mathrm{H}_{2} \mathrm{O} / \mathrm{HCl}$ was 1:388:527:0.175. The mixture was stirred for $1 \mathrm{~h}$ at $80{ }^{\circ} \mathrm{C}$, then kept under static conditions at the same temperature for 4 days. The resulting gel/precipitate was filtered off; washed successively with water, ethanol, acetone and water; and then freeze-dried overnight.

Characterization. Solid state NMR: ${ }^{29} \mathrm{Si}$ and ${ }^{13} \mathrm{C}$ solid state NMR spectra were recorded using the magic-angle spinning (MAS) and the cross-polarization/magic-angle spinning (CP/MAS) modes, 
respectively, on a Varian VNMRS $400 \mathrm{MHz}$ spectrometer using a two-channel probe with 7.5 -mm-diameter-sized $\mathrm{ZrO}_{2}$ rotors. Tetramethylsilane was used as reference for the chemical shifts.

Scanning electron microscopy (SEM): SEM micrographs were obtained with a Hitachi S-4800 apparatus after platinum metallization.

Transmission electron microscopy (TEM): TEM micrographs were obtained using a LEO $906 \mathrm{E}$ Leica. The images were printed as photographs using Kodak Electron film negatives. TEM micrographs were also obtained using a JEOL 1200 EX2 apparatus equipped with a SIS Olympus Quemesa 11 Mpixel camera. Pictures were treated using the ImageJ software.

Atomic force microscopy (AFM): The AFM images were recorded using an AFM Nanoscope Instruments equipment in tapping mode with a super-sharp silicon probe having a radius of $10 \mathrm{~nm}$, resonance frequency of $330 \mathrm{kHz}$, and spring constant of $42 \mathrm{~N} \mathrm{~m}^{-1}$. The images were deconvoluted considering the probe's shape using WSXM software. ${ }^{24}$ To improve the image quality, tools to flatten and eliminate line noise and a Gaussian filter were employed. The same tip was employed in all the images recorded to avoid the influence of the tip radius variations on the square roughness values.

Polarized optical microscopy (POM): POM images were recorded using an Optika B-600POL microscope equipped with a 8 megapixel digital photo camera. The images were analyzed using Optika Vision Pro software.

$\mathrm{X}$-ray diffraction (XRD): The XRD patterns were recorded at room temperature with a Rigaku Geigerflex $\mathrm{D} / \mathrm{max}-\mathrm{c}$ diffractometer system using monochromated $\mathrm{Cu} \mathrm{K}_{\alpha}$ radiation $(\lambda=1.54 \AA$ ) over the $2 \theta$ range of between 4 and $70^{\circ}$ at a resolution of $0.05^{\circ}$. The samples were not subject to any thermal pretreatment.

Small angle X-ray scattering (SAXS): The SAXS spectra were recorded at the National Synchrotron Light Laboratory (LNLS), Campinas (Brazil), using a SAXS beamline that provides a monochromatic $(\lambda=1.608 \AA)$ and horizontally focused beam. A vertical position-sensitive X-ray detector and a multichannel analyzer were used to record the SAXS intensity, $I(q)$, as a function of modulus of the scattering vector $q=4 \pi / \lambda \sin (\varepsilon / 2), \varepsilon$ being the X-ray scattering angle. The parasitic scattering intensity from air, slits, and windows was subtracted from the total intensity. The scattering intensity was also normalized by taking into account the varying intensity of the direct X-ray beam, sample absorption, and sample thickness.

Fourier transform infrared (FT-IR): The FT-IR spectra were acquired at room temperature in the $4000-400 \mathrm{~cm}^{-1}$ range by averaging 64 scans at a resolution of $4 \mathrm{~cm}^{-1}$ and using a Unicam FT-IR spectrophotometer. To prepare the pellets, $2 \mathrm{mg}$ portions of the samples were mixed and finely ground with $175 \mathrm{mg}$ of potassium bromide ( $\mathrm{KBr}$, Merck, spectroscopic grade) and pressed under vacuum. Prior to recording the spectra, the disks were stored in an oven under vacuum at $80^{\circ} \mathrm{C}$ until the levels of adsorbed water were reduced.

Fourier transform Raman (FT-Raman): The FT-Raman spectra were recorded at room temperature with a Bruker RFS 100/S spectrometer equipped with a near-infrared Nd:YAG laser with wavelength excitation $(1064 \mathrm{~nm}$ at $400 \mathrm{~mW})$. The spectra were collected over the $3200-300 \mathrm{~cm}^{-1}$ range by averaging 200 scans at a maximum resolution of $4 \mathrm{~cm}^{-1}$.

Curve-fitting procedures: To evaluate broad FT-IR and FTRaman bands and to identify underlying spectral components, the iterative least-squares curve-fitting procedure in PeakFit (version 4$)^{25}$ was used. The best fit of the experimental data was obtained by varying the frequency, bandwidth, and intensity of the bands and by using Gaussian/Voight shapes. A linear baseline correction with a tolerance of $0.2 \%$ was employed. The standard errors of the curve-fitting procedure were $<0.003$.

Two dimensional (2D) correlation FT-IR spectroscopic analysis: In 2D spectroscopy, dynamic variations in spectra (e.g., intensity changes and band position shifts, among others) produced by an external sample perturbation are mathematically cross-correlated to construct a $2 \mathrm{D}$ correlation contour map. By spreading peaks over the second dimension, this technique provides an enhanced discrimination of those vibration modes that selectively respond to the perturbation, being thus of particular interest in the case of complex spectra composed of many overlapped peaks. ${ }^{26-32}$ The $2 \mathrm{D}$ correlation spectra (or 2D correlation contour maps) generated by crosscorrelation analysis of dynamic fluctuations of spectral signals induced by an external stimulus - the synchronous and asynchronous spectra-consist of two orthogonal components defined by two independent wavenumbers $\left(\bar{v}_{1}, \bar{v}_{2}\right)$. Each of these $2 \mathrm{D}$ correlation spectra carries very distinct and useful information: the synchronous $2 \mathrm{D}$ correlation spectrum $\left(\Phi\left(\bar{v}_{1}\right.\right.$, $\left.\bar{v}_{2}\right)$ ) represents the simultaneous (or coincidental) changes of spectral intensities measured at $\bar{v}_{1}$ and $\bar{v}_{2}$ within the interval between $t_{\min }$ and $t_{\max }$ of the externally defined variable $t$, and the asynchronous $2 \mathrm{D}$ correlation spectrum $\left(\psi\left(\bar{v}_{1}, \bar{v}_{2}\right)\right)$ represents sequential (or successive) changes of spectral intensities measured at $\bar{v}_{1}$ and $\bar{v}_{2}$. The FT-IR 2D correlation spectroscopic analysis was carried out using the following procedure:

(a) The reference spectrum, $\bar{y}(\bar{v})$, was subtracted from each of the experimental spectra, $y(\bar{v}, t)$, to obtain the dynamic spectra, $\tilde{y}(\bar{v}, t)$ (mean-centered procedure)..$^{28,31,32}$ In the present study, the reference spectrum, $\bar{y}(\bar{v})$, was considered as the $t$-averaged of $y(\bar{v}, t)$. The resulting mean-centered dynamic spectra represent the relative variations of spectral intensity as a function of the wavenumber, $\bar{v}$, and for each length of alkylene chain of the central spacer, $S_{1}$ (inducing perturbation), of the $\mathrm{C}_{10} \mathrm{C}_{n} \mathrm{C}_{10}$ hybrids, represented by $t$ in the variables just described.

(b) For the set of dynamic spectra, the $2 \mathrm{D}$ correlation spectra were then obtained using a numerical computational procedure based on a form of discrete Hilbert transform, as described by Noda. ${ }^{28,31,32}$ The synchronous $2 \mathrm{D}$ correlation intensities were calculated by the following equation:

$$
\Phi\left(\bar{v}_{1}, \bar{v}_{2}\right)=\frac{1}{n-1} \sum_{j=1}^{n} y\left(\bar{v}_{1}, t_{j}\right) \cdot y\left(\bar{v}_{2}, t_{j}\right)
$$

The asynchronous $2 \mathrm{D}$ intensities were determined using the following expression:

$$
\Psi\left(\bar{v}_{1}, \bar{v}_{2}\right)=\frac{1}{n-1} \sum_{j=1}^{n} y\left(\bar{v}_{1}, t_{j}\right) \cdot \sum_{k=1}^{n} H_{j k} \cdot y\left(\bar{v}_{2}, t_{k}\right)
$$

where $H_{j k}$ are the elements of the Hilbert-Noda transformation matrix, given by ${ }^{28,31,32}$

$$
H_{j k}= \begin{cases}0 & \text { if } j=k \\ \frac{1}{\pi(k-j)} & \text { otherwise }\end{cases}
$$


Here, $\bar{v}$ represents the IR wavenumber, and $n$ is the total number of dynamic spectra. All the calculations were performed using a tailor-made code. ${ }^{33}$

(c) On the basis of the proposed shading convention for $2 \mathrm{D}$ correlation spectra, ${ }^{30}$ in the present data, the following color convention was adopted: positive values in the synchronous and asynchronous spectra are represented in red, whereas negative values are represented in dark blue. The data were analyzed on the basis of Noda's rules. ${ }^{28,29}$ According to these rules, a positive cross-peak located at coordinates $\left(\bar{v}_{1}, \bar{v}_{2}\right)$ in a synchronous spectrum $\left(\Phi\left(\bar{v}_{1}, \bar{v}_{2}\right)>0\right)$ indicates that the intensity changes of the autopeaks centered at $\left(\bar{v}_{1}, \bar{v}_{1}\right)$ and $\left(\bar{v}_{2}, \bar{v}_{2}\right)$ take place in the same direction, that is, they either increase or decrease. In contrast, a negative synchronous cross-peak located at the same coordinates $\left(\Phi\left(\bar{v}_{1}, \bar{v}_{2}\right)<0\right)$ indicates that the intensity changes of the respective autopeaks occur in opposite directions, that is, while the change at one of the spectral coordinates occurs in the increasing direction, the change at the other spectral coordinate occurs in the decreasing direction. In an asynchronous spectrum, a positive cross-peak $\left(\psi\left(\bar{v}_{1}, \bar{v}_{2}\right)>0\right)$ indicates that the spectral intensity change observed at $\bar{v}_{1}$ occurs predominantly before that observed at $\bar{v}_{2}$ in the sequential order of the change-inducing variable $t$. A negative asynchronous cross-peak $\left(\psi\left(\bar{v}_{1}, \bar{v}_{2}\right)<0\right)$ indicates the opposite. These rules apply only if the corresponding synchronous cross-peaks at the same coordinates are positive. Otherwise (i.e., if the synchronous cross-peaks at the same coordinates are negative), the sequential order of the events occurring at the two spectral coordinates described above is reversed.

(d) The choice of the minimum threshold intensity level to consider in a contour map is arbitrary, although critical. A too high threshold may obscure or omit fine features of the correlation spectrum, whereas a too low threshold might overaccentuate noise and baseline distortions and lead to the appearance of parasitic correlation peaks. ${ }^{27,28,31}$ In the present study, the minimum threshold considered was $5 \%$ of the maximum absolute value of the contour map.

Photoluminescence (PL): The PL spectra were recorded at room temperature and at $12 \mathrm{~K}$ with a modular double grating excitation spectrofluorimeter with a Triax 320 emission monochromator (Fluorolog-3, Jobin Yvon-Spex Horiba Scientific) coupled to a R928 Hamamatsu photomultiplier, using the front face acquisition mode. The excitation source was a $450 \mathrm{~W} \mathrm{Xe}$ arc lamp. The emission spectra were corrected for detection and optical spectral response of the spectrofluorimeter, and the excitation spectra were corrected for the spectral distribution of the lamp intensity using a photodiode reference detector. The lifetime measurements were acquired with the setup described for the luminescence spectra using a pulsed $\mathrm{Xe}-\mathrm{Hg}$ lamp ( $6 \mu$ s pulse at half width and $20-30 \mu$ s tail). The absolute emission quantum yields were measured at room temperature using a quantum yield measurement system C9920-02 from Hamamatsu with a $150 \mathrm{~W}$ xenon lamp coupled to a monochromator for wavelength discrimination, an integrating sphere as sample chamber, and a multichannel analyzer for signal detection. Three measurements were made for each sample so that the average value is reported. The method is accurate to within $10 \%$.

\section{RESULTS AND DISCUSSION}

The ${ }^{29}$ Si MAS NMR spectra of the $\mathrm{C}_{10} \mathrm{C}_{n} \mathrm{C}_{10}$ materials display three broad signals centered at $-47,-58$, and $-68 \mathrm{ppm}$ (Figure $\mathrm{S} 1$ and Table $\mathrm{S} 1$ of the Supporting Infomation) ascribed to $\mathrm{T}^{1}$ $\left(\mathrm{C}-\mathrm{Si}(\mathrm{OSi})(\mathrm{OH})_{2}\right), \mathrm{T}^{2}\left(\mathrm{C}-\mathrm{Si}(\mathrm{OSi})_{2}(\mathrm{OH})\right)$, and $\mathrm{T}^{3}(\mathrm{C}-\mathrm{Si}-$ $\left.(\mathrm{OSi})_{3}\right)$ silicon sites, respectively. The condensation degrees deduced (Table S1) are on the same order of magnitude as those reported previously for the lamellar $\mathbf{L} 12$ material $^{\text {10,12,15 }}$ and more recently for the sponge-like $\mathbf{L} 12 \mathrm{D}$ material. ${ }^{17}$ These findings suggest that in the $\mathrm{C}_{10} \mathrm{C}_{n} \mathrm{C}_{10} \mathrm{BSs}$, the siloxane framework is a $2 \mathrm{D}$ network composed of linear polymer siloxane linkages. However, the spectra of Figure S1 demonstrate that, although the dominating silicon sites in the $\mathrm{C}_{10} \mathrm{C}_{n} \mathrm{C}_{10}$ materials are $\mathrm{T}^{2}$ units, $\mathrm{T}^{1}$ and $\mathrm{T}^{3}$ type units are also present, revealing partial variation in the siloxane linkages. The absence of $\mathrm{Q}$ type $\left(\mathrm{SiO}_{4}\right)$ resonances between -90 and $-120 \mathrm{ppm}$ in the ${ }^{29} \mathrm{Si}$ MAS NMR spectra (not shown) is a proof of the preservation of the $\mathrm{C}-\mathrm{Si}$ bonds in the $\mathrm{C}_{10} \mathrm{C}_{n} \mathrm{C}_{10}$ samples. The ${ }^{13} \mathrm{C} \mathrm{CP} / \mathrm{MAS}$ NMR spectra of the hybrid samples (Figure S2) also provide evidence of the preservation of the $\mathrm{Si}-\mathrm{C}$ bond (peak located at $\sim 14 \mathrm{ppm}$ ) and also prove that no cleavage of the functional groups of the precursor molecule (i.e., central spacer alkylene chains, side spacer decylene chains and urea cross-links) occurred during the synthesis of the $\mathrm{C}_{10} \mathrm{C}_{n} \mathrm{C}_{10} \mathrm{BSs}$. The absence of the peaks characteristic of ethoxyl carbon atoms at $\sim 58$ and $18 \mathrm{ppm}$ demonstrate that the hydrolysis reaction was complete.

Analysis of the SEM images reveals that the morphology of $\mathrm{C}_{10} \mathrm{C}_{7} \mathrm{C}_{10}$ is rather irregular (Figure $1 \mathrm{a}, \mathrm{b}$ ), whereas that of the $\mathrm{C}_{10} \mathrm{C}_{9} \mathrm{C}_{10}$ and $\mathrm{C}_{10} \mathrm{C}_{10} \mathrm{C}_{10}$ samples closely resembles that of L12D. ${ }^{17}$ Both materials form microobjects with a sponge-like morphology (Figure 1c, e, respectively), consisting of very thin, folded films assembled along an edge-to-face fashion $(n=9$, Figure 1d) or entangled folded ribbons $(n=10$, Figure 1f). In $\mathrm{C}_{10} \mathrm{C}_{11} \mathrm{C}_{10}$, the ribbons appear considerably more folded, forming less-regular objects (Figure $1 \mathrm{~g}, \mathrm{~h}$ ). The process ends up in $\mathrm{C}_{10} \mathrm{C}_{12} \mathrm{C}_{10}$ with the production of $10-\mu \mathrm{m}$-diameter, dense, homogeneous spheroidal particles (Figure 1i), which tend to link to each other (Figure $1 \mathrm{j}$ ). The increasing contribution of the folding process to which the thin films are subject in these materials as the length of the central spacer increases is clearly recognized in the TEM images shown in Figure 2. The intrinsic ordered nanostructure of the films/ribbons is perfectly evident in the case of samples with $n=9$ (Figure $2 b$ ), $n=10$ (Figure 2c, d) and $n=12$ (Figure $2 \mathrm{~h}$ ). Additional proofs of the organized texture of $\mathrm{C}_{10} \mathrm{C}_{12} \mathrm{C}_{10}$ and, in particular, $\mathrm{C}_{10} \mathrm{C}_{10} \mathrm{C}_{10}$ have been obtained by AFM upon scanning the surface of the samples in tapping mode (Figure 3c, b, respectively). The 3D topographic perspective of the BS with $n=10$ is given in Figure S3. The organization fashion observed in both samples is, however, less well distinguishable in the case of the material with $n=9$ (Figure 3a). The anisotropic nature of $\mathrm{C}_{10} \mathrm{C}_{10} \mathrm{C}_{10}$ is demonstrated in the POM image recorded between crossed polarizers (Figure S4). The exhibited birefringence indicates submicrometric anisotropy.

The XRD patterns of selected samples exhibit completely different profiles in the high $q$ range $\left(q>10 \mathrm{~nm}^{-1}\right)$ (Figure 4). While the $\mathrm{C}_{10} \mathrm{C}_{7} \mathrm{C}_{10}$ material produces a broad, ill-defined and asymmetric peak centered at about $15 \mathrm{~nm}^{-1}$, the intensity maximum of the band is shifted to about $15.7 \mathrm{~nm}^{-1}$ for $n=9$ and 11 and a shoulder is visible in the lower $q$ side, especially in the pattern of the former hybrid. In the case of the BS with the 


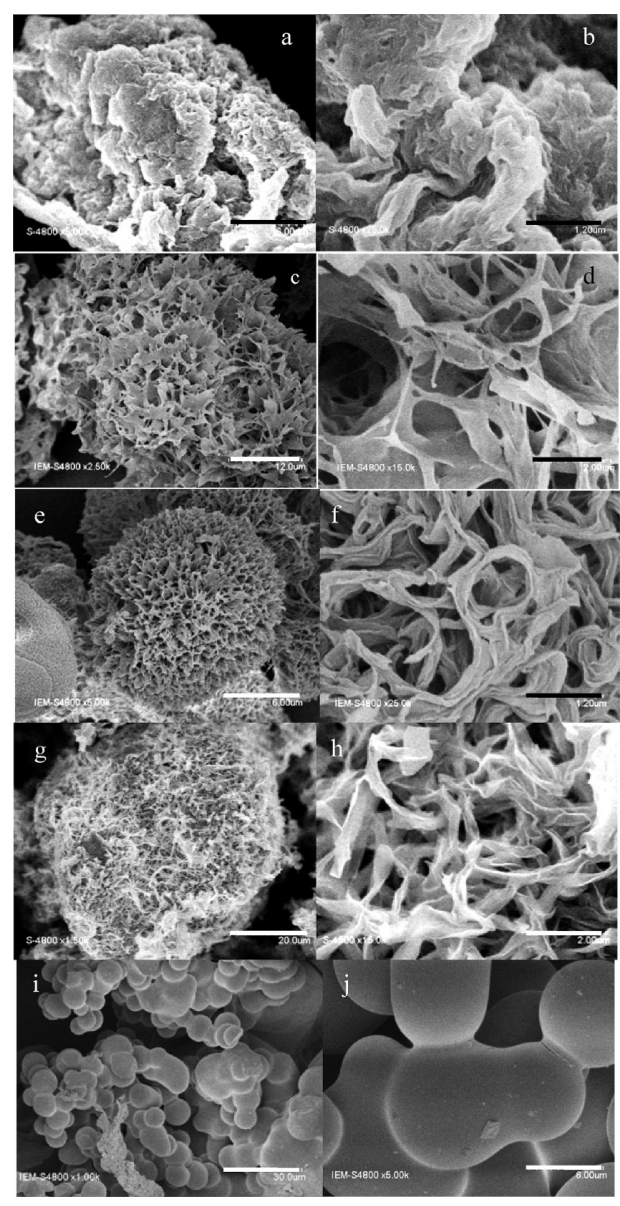

Figure 1. SEM images of the $\mathrm{C}_{10} \mathrm{C}_{n} \mathrm{C}_{10}$ bridged silsesquioxanes with $n=7$ (scale bars $=6(\mathrm{a})$ and $1.20 \mu \mathrm{m}(\mathrm{b})), n=9($ scale bars $=12(\mathrm{c})$ and $2 \mu \mathrm{m}(\mathrm{d})), n=10($ scale bars $=6(\mathrm{e})$ and $1.20 \mu \mathrm{m}(\mathrm{f})), n=11($ scale bars $=$ $20(\mathrm{~g})$ and $2 \mu \mathrm{m}(\mathrm{h}))$, and $n=12($ scale bars $=30(\mathrm{i})$ and $6 \mu \mathrm{m}(\mathrm{j}))$.

longest central spacer $\mathrm{S}_{1}\left(\mathrm{C}_{10} \mathrm{C}_{12} \mathrm{C}_{10}\right)$ the band profile becomes better resolved and two peaks centered at 14.7 and $16.2 \mathrm{~nm}^{-1}$ are discerned (Figure 4). Curve-fitting of the band envelopes performed between 12 and $19 \mathrm{~nm}^{-1}$ by means of Gaussian shapes allowed us to identify four components in the XRD patterns of the samples with $n=7,9,11$, and 12 . The component at lowest $q$, centered at $13.54 \mathrm{~nm}^{-1}\left(d_{1}=0.464 \mathrm{~nm}\right)$, is attributed to the separation between two neighboring urea groups of the ureaurea hydrogen-bonded array. ${ }^{15-17}$ The characteristic component associated with ordering within the siloxane domains is centered at $14.65 \mathrm{~nm}^{-1}\left(d_{2}=0.429 \mathrm{~nm}\right) .^{15-17}$ The remaining two components, centered at $15.85 \mathrm{~nm}^{-1}\left(d_{3}=0.392 \mathrm{~nm}\right)$ and $17.15 \mathrm{~nm}^{-1}\left(d_{4}=0.366 \mathrm{~nm}\right)$, are ascribed to chain-chain spacings, indicating the occurrence of gauche and all-trans conformers in the alkylene chains, respectively. ${ }^{15-17}$

In the low $q$ range $\left(q<10 \mathrm{~nm}^{-1}\right)$, the XRD patterns of the $\mathrm{C}_{10} \mathrm{C}_{n} \mathrm{C}_{10}$ BSs display narrow peaks that correspond presumably to the higher-order (i) harmonics of the fundamental reflection located at $q<2 \mathrm{~nm}^{-1}$ (Figure 4). This hypothesis is confirmed by the presence of a weak and ill-defined peak at $q \approx 1.47-$ $1.55 \mathrm{~nm}^{-1}$ in the SAXS patterns of the $\mathrm{C}_{10} \mathrm{C}_{n} \mathrm{C}_{10}$ hybrids with $n=9,10$, and 12 reproduced in Figure 5a. Unfortunately, this peak is masked by the intense scattering produced by the hybrid particles. In fact, the linear dependency (slope close to -4) observed in the low $q$ region of the $\log$ - log plot depicted in the

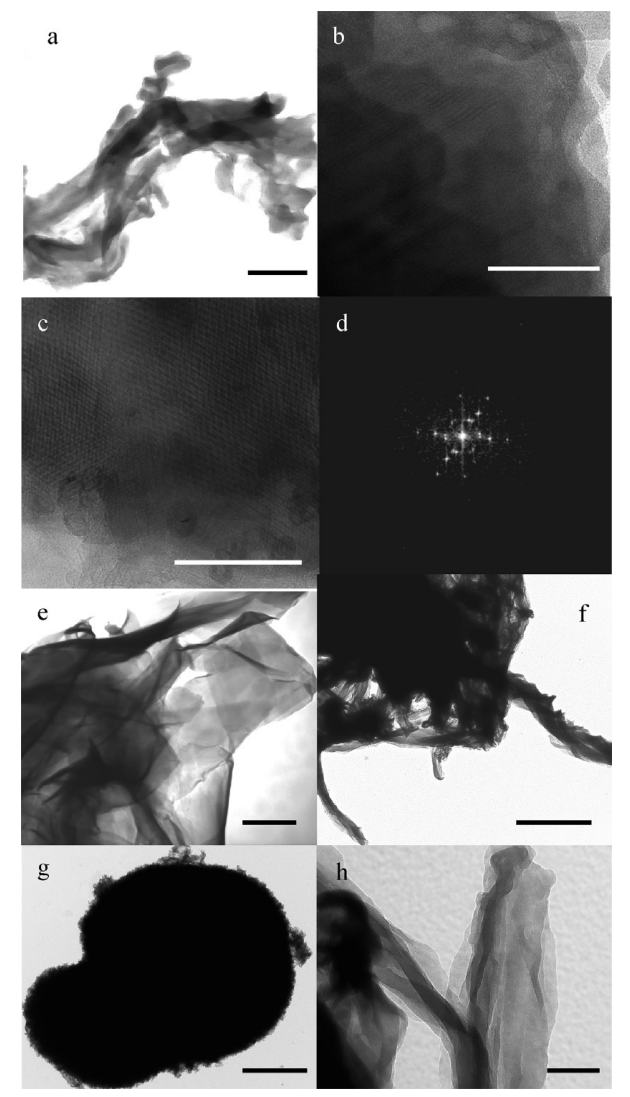

Figure 2. TEM images of the $\mathrm{C}_{10} \mathrm{C}_{n} \mathrm{C}_{10}$ bridged silsesquioxanes with $n=7$ (a) scale bar $=173 \mathrm{~nm} ; n=9$ (b) scale bar $=100 \mathrm{~nm} ; n=10$ (c) scale bar $=100 \mathrm{~nm}$; and (d) Fast Fourier Transform image; $n=11$ (e) scale bar $=435 \mathrm{~nm} ; n=12$ (f) scale bar $=1 \mu \mathrm{m},(\mathrm{g})$ scale bar $=1 \mu \mathrm{m}$ and (h) scale bar $=100 \mathrm{~nm}$.

inset of Figure 5a is in agreement with the Porod power law decay expected for a two-phase system with a well-defined interface. Thus, the two peaks at $q>1 \mathrm{~nm}^{-1}$ correspond to the reflections of inner particles' crystalline structure.

The position of the higher-order Bragg peaks follows the sequence characteristic of a lamellar structure in which the interlamellar distance, $l$, is given by $l=2 \pi i / q_{i}(i=1,2,3, \ldots)$. The $l$ spacing values calculated on the basis of the SAXS data for the $\mathrm{C}_{10} \mathrm{C}_{n} \mathrm{C}_{10}$ hybrids are $4.09 \pm 0.01 \mathrm{~nm}$ for $n=9,4.13 \pm$ $0.02 \mathrm{~nm}$ for $n=10$, and $4.24 \pm 0.02 \mathrm{~nm}$ for $n=12$. The increase in $l$ with $n$ supports that the length of the alkylene chains of the central spacer is intimately correlated with the interlamellar distance. This result allows inferring that the hybrids have a lamellar structure composed of 2D siliceous domains separated by the alkylene chains. Assuming an average $\mathrm{C}-\mathrm{C}$ distance of $0.13 \mathrm{~nm}$, the addition of $3 \mathrm{CH}_{2}$ groups to a nonylene chain would be expected to result in an increment of $l$ equal to $0.39 \mathrm{~nm}$, which is considerably higher (it corresponds grosso modo to a 3-fold increase) than the value found experimentally (4.24-4.09= $0.15 \mathrm{~nm})$.

In the graph of Figure $5 b$, the experimental $l$ spacings are compared with those calculated if the alkylene chains of the central and side spacers $\left(S_{1}\right.$ and $S_{2}$, respectively) adopted exclusively fully extended all-trans zigzag conformations. The trend observed allows inferring that all-trans and gauche conformers coexist in the three samples. We can further conclude from Figure $5 b$ that there is not a linear relationship between the increase of the length of the 


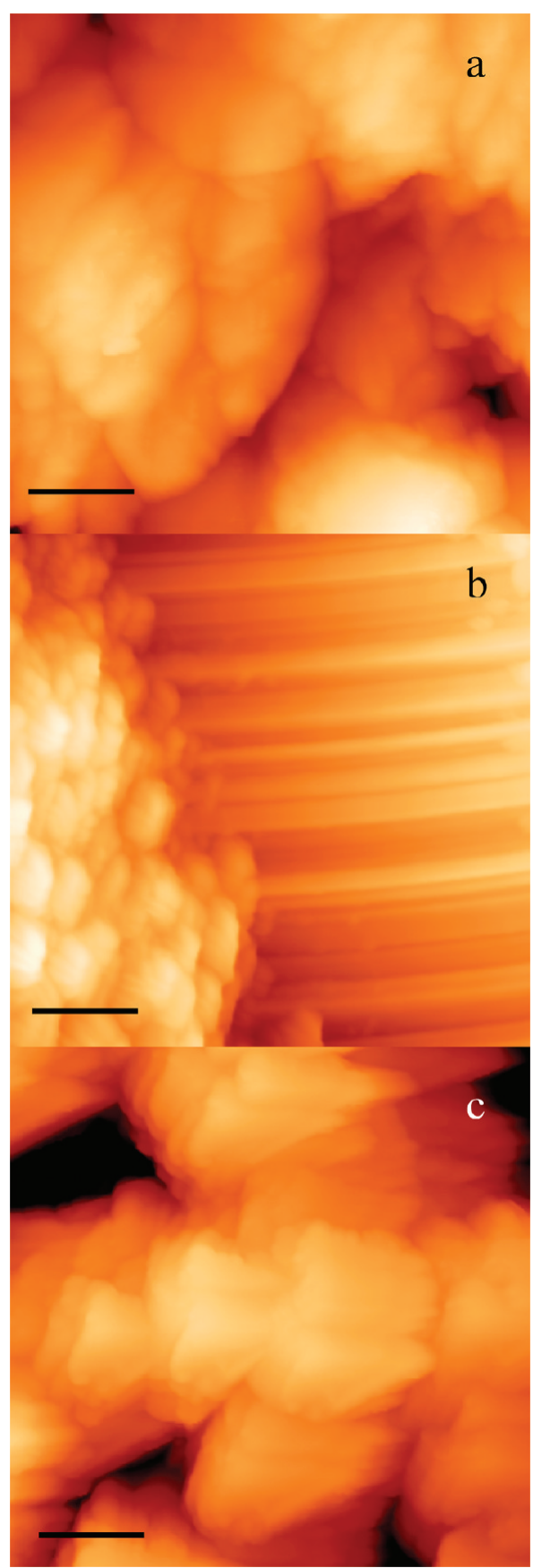

Figure 3. Plane AFM images of the $\mathrm{C}_{10} \mathrm{C}_{n} \mathrm{C}_{10}$ bridged silsesquioxanes with $n=9$ (a), $n=10$ (b), and $n=12$ (c). Scale bars $=400 \mathrm{~nm}$.

central spacer $\mathrm{S}_{1}$ of $\mathrm{C}_{10} \mathrm{C}_{9} \mathrm{C}_{10}, \mathrm{C}_{10} \mathrm{C}_{10} \mathrm{C}_{10}$, and $\mathrm{C}_{10} \mathrm{C}_{12} \mathrm{C}_{10}$ and the deviation of the experimental $l$ values from those calculated for perfect all-trans alkylene chains $(\Delta l=0.59,0.68$, and $0.83 \mathrm{~nm}$ for $n=9,10$, and 12, respectively). Therefore, it is clear that upon introduction of more methylene groups into the central spacer $S_{1}$, the proportion of gauche conformers increases, and the alkylene chains become less well packed, a process that ultimately leads to the compression of the siliceous layers.

On the basis of these data, it is reasonable to propose that the alkylene chains of the $\mathrm{C}_{10} \mathrm{C}_{n} \mathrm{C}_{10}$ samples with $n=9,10$, and 12 are very likely not perpendicularly oriented with respect to the $2 \mathrm{D}$ siliceous layers. To determine the average coherence length,

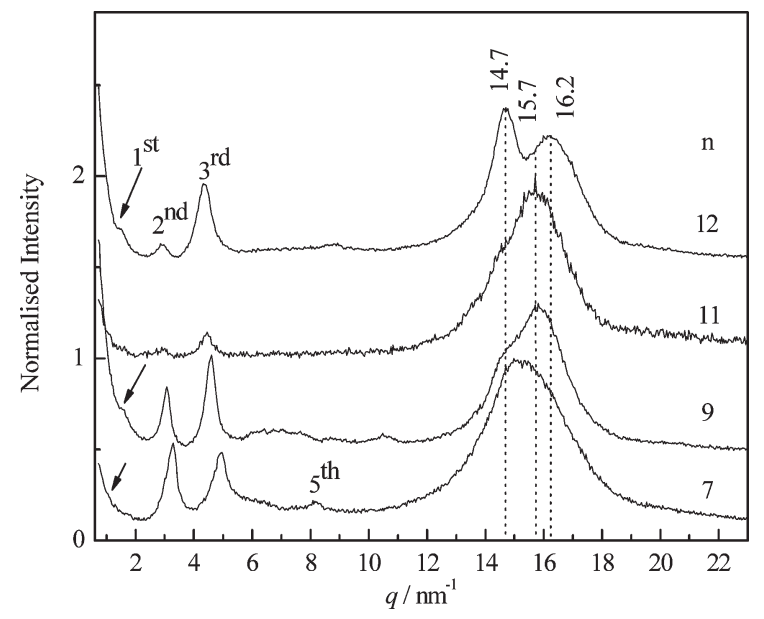

Figure 4. XRD patterns of selected $\mathrm{C}_{10} \mathrm{C}_{n} \mathrm{C}_{10}$ bridged silsesquioxanes.
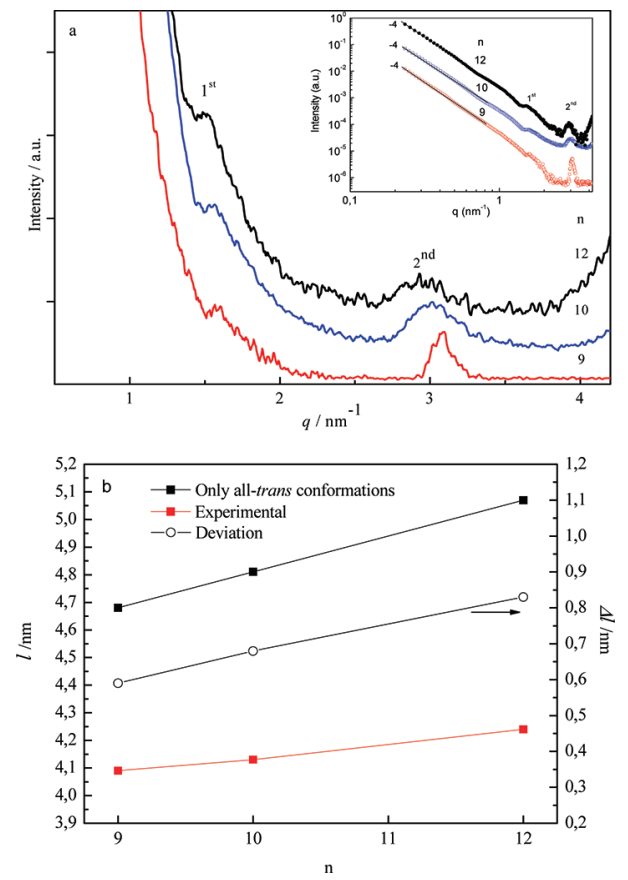

Figure 5. SAXS patterns of selected $\mathrm{C}_{10} \mathrm{C}_{n} \mathrm{C}_{10}$ bridged silsesquioxanes (a), chain length dependence of the characteristic interlamellar distance, $l$ (left axis), and of the deviation of a complete all-trans conformations situation (b). The lines drawn in panel $b$ are just guides for the eyes.

$L$, of the lamellar order of the three hybrids examined by SAXS, the integral breadth of the second-order diffraction peak observed in the SAXS patterns $(B)$ was corrected from the instrumental broadening $(b)$ by using a well-crystallized poly(oxyethylene) $)^{34}$ as standard reference of experimental aberrations. Assuming that the corrected integral breadth $\left(\beta^{2}=B^{2}-b^{2}\right)^{35}$ is essentially due to the size effects, the coherence length of the lamellar order, deduced by means of the Scherrer equation $(L=$ $4 \pi / \beta),{ }^{35}$ was $105 \pm 3 \mathrm{~nm}$ for $\mathrm{C}_{10} \mathrm{C}_{9} \mathrm{C}_{10}$ and $33 \pm 2 \mathrm{~nm}$ for samples with $n=10$ and 12 , respectively, corresponding to $\sim 25 \pm 1$ and $8.0 \pm 0.7$ lamellae, respectively.

Despite the conclusions retrieved from SAXS data, which suggest the presence of almost completely stretched chains, the absence of intramolecular cyclization cannot be discarded. 
However, if present, it must be negligible and the result of a side reaction.

Valuable information regarding the conformational disorder of the alkylene chains can be retrieved from the intense, broad, and ill-defined peak that dominates the ${ }^{13} \mathrm{C} \mathrm{CP} / \mathrm{MAS} N \mathrm{NR}$ spectra from 40 to $25 \mathrm{ppm}$ (Figure S2). Two contributions at $\sim 33$ and $30 \mathrm{ppm}$ are clearly discerned: the former resonance is due to the carbon atoms of ordered and densely packed alkylene chains in all-trans zigzag conformations, whereas the more shielded signal is produced by the carbon atoms of disordered chains adopting gauche conformations. ${ }^{36-38}$ The shoulder visible at $\sim 35 \mathrm{ppm}$ (especially detected in the spectra of the $\mathrm{C}_{10} \mathrm{C}_{11} \mathrm{C}_{10}$ material (Figure $\mathrm{S} 2 \mathrm{~b}$ ) suggests that crystalline alkylene chains with different packing structures coexist in these samples. ${ }^{36}$ Attempts to calculate the all-trans/gauche conformational ratio through curve-fitting of this broad, prominent peak were not successful, and thus, any conclusions drawn from these data were considered to be highly speculative. Comparison of the peak profile of the $\mathrm{C}_{10} \mathrm{C}_{n} \mathrm{C}_{10}$ materials studied suggests that the materials with even $n$ appear to be more disordered than those with odd $n$, corroborating the conclusions drawn from SAXS data.

To gain complementary insight into the degree of chain packing and the trans/gauche conformational ratio in the $\mathrm{C}_{10} \mathrm{C}_{n} \mathrm{C}_{10}$ hybrid samples, we recorded the FT-IR and FT-Raman spectra and examined the following diagnostic modes of the alkylene chains: (1) the symmetric and asymmetric stretching $\mathrm{CH}_{2}$ modes $\left(v_{\mathrm{s}} \mathrm{CH}_{2}\right.$ and $v_{\mathrm{a}} \mathrm{CH}_{2}$, respectively) and (2) the $\mathrm{CH}_{2}$ bending $\left(\delta \mathrm{CH}_{2}\right)$ mode.

The location and intensity of the $v_{\mathrm{s}} \mathrm{CH}_{2}$ mode is complicated due to Fermi resonance between the $v_{\mathrm{s}} \mathrm{CH}_{2}$ fundamental with the many overtones of the $\delta \mathrm{CH}_{2}$ vibrations. ${ }^{38-42}$ The $v_{\mathrm{a}} \mathrm{CH}_{2}$ mode is affected by coupling to the torsional and rotational motions of the chain. ${ }^{38-42}$ In the Raman spectrum of ordered alkyl chains (all-trans conformations), the $v_{\mathrm{a}} \mathrm{CH}_{2}$ mode emerges as a strong band in the $2884-2878 \mathrm{~cm}^{-1}$ interval, whereas the $v_{\mathrm{s}} \mathrm{CH}_{2}$ mode produces bands at 2930 (weak), 2900-2898 (medium), and $2850-2844 \mathrm{~cm}^{-1}$ (strong). ${ }^{38-42}$ In the case of disordered alkylene chains (gauche conformations), the $v_{\mathrm{a}} \mathrm{CH}_{2}$ mode appears at $2897-2890 \mathrm{~cm}^{-1}$, and the $\nu_{s} \mathrm{CH}_{2}$ bands are typically seen at 2920 (weak), 2904 (medium), and 2858$2853 \mathrm{~cm}^{-1}$ (strong). ${ }^{38,41,42} \mathrm{Up}$-shifting and band-broadening are indicative of an increasing proportion of gauche conformers.

The inspection of the $\delta \mathrm{CH}_{2}$ region is of interest, since the frequency, intensity and band shape of the $\delta \mathrm{CH}_{2}$ mode are sensitive to interchain interaction and to the packing arrangement of the chains. ${ }^{35,43}$ A higher frequency $\left(\sim 1472 \mathrm{~cm}^{-1}\right)$ in the IR spectra indicates ordering of the alkylene chains in all-trans conformations (crystalline state), whereas lower frequency $\left(\sim 1466 \mathrm{~cm}^{-1}\right)$, band broadening, and decreasing intensity indicate an increase in chain motion (liquid-like state) and, therefore, a larger gauche/trans conformer ratio. $^{43}$

The FT-Raman spectra of the $\mathrm{C}_{10} \mathrm{C}_{n} \mathrm{C}_{10}$ samples with even $n$ and odd $n$ in the $\nu \mathrm{CH}_{2}$ region (depicted in Figure S5a,b, respectively) are dominated by two bands at 2885 (very strong, vS)/ $2857 \mathrm{~cm}^{-1}$ (strong, S) and $2884(\mathrm{vS}) / 2858 \mathrm{~cm}^{-1}(\mathrm{~S})$, respectively. In both cases, an intense event, manifested as a shoulder and located at 2850 and $2848 \mathrm{~cm}^{-1}$, respectively, is discerned (Figure S5a,b, respectively). The features at $\sim 2885$ and $2850 \mathrm{~cm}^{-1}$ are attributed to the $v_{\mathrm{a}} \mathrm{CH}_{2}$ and $v_{\mathrm{s}} \mathrm{CH}_{2}$ modes of all-trans conformers of the alkylene chains. ${ }^{39-43}$ The component at $\sim 2858 \mathrm{~cm}^{-1}$, also associated with the $v_{\mathrm{s}} \mathrm{CH}_{2}$ mode, is characteristic of gauche conformers. ${ }^{39,42,43}$ The peak height ratio $(r)$ of the $v_{\mathrm{a}} \mathrm{CH}_{2}$ and $v_{\mathrm{s}} \mathrm{CH}_{2}$ bands is a valuable tool to determine the conformational disorder of the alkylene chains and their packing arrangement. ${ }^{39}$ High values $(1.61-1.72)$ are produced by crystalline alkylene chains, whereas chains in the amorphous state give rise to values that range from 1.39 to $1.48 .^{39}$ The dependence of the intensity ratio $r=I_{2885} / I_{2850}$ with the number of carbon atoms of the alkylene chains of the central spacer $\mathrm{S}_{1}$ of the $\mathrm{C}_{10} \mathrm{C}_{n} \mathrm{C}_{10}$ materials is represented in Figure 7. The trend observed suggests that all the alkylene chains of the $\mathrm{C}_{10} \mathrm{C}_{7} \mathrm{C}_{10}$ sample (i.e., the chains of the side spacers $S_{2}$ and that of the central spacer $S_{1}$ ) are completely disordered and, consequently, adopt gauche conformations. It may be further inferred from the plot of Figure 7 that in hybrids with a longer central spacer $S_{1}(n>7)$ the proportion of fully stretched and densely packed alkylene chains (all-trans conformers) is enhanced considerably. In $\mathrm{C}_{10} \mathrm{C}_{9} \mathrm{C}_{10}$, the value attained for $r$ practically coincides with the minimum value reported for solid $n$-alkanes, suggesting that the presence of two decylene side chains and one central nonylene chain promotes the highest degree of order and the tightest packing. In addition, these data also point out that samples with $n=10,11$, and 12 contain more gauche conformers than $\mathrm{C}_{10} \mathrm{C}_{9} \mathrm{C}_{10}$.

The bands centered at $\sim 1479$ and $1466 \mathrm{~cm}^{-1}$ in the $\delta \mathrm{CH}_{2}$ region of the FT-IR spectra of the $\mathrm{C}_{10} \mathrm{C}_{n} \mathrm{C}_{10}$ hybrids (Figure S6) reveal the occurrence of ordered and disordered alkylene chains and, thus, the coexistence of all-trans and gauche conformers. ${ }^{43,44}$ The band at $\sim 1440 \mathrm{~cm}^{-1}$ discerned in the same spectra represents further evidence of the existence of gauche bonds. ${ }^{45,46}$ Interestingly, it can be inferred from the comparison between parts a and $\mathrm{b}$ of Figure $\mathrm{S} 6$ that the $\delta \mathrm{CH}_{2}$ mode is sensitive to the parity of the number of carbon atoms of the alkylene chain of the central spacer. Although the $\mathrm{C}_{10} \mathrm{C}_{n} \mathrm{C}_{10}$ hybrids with odd $n$ display a shoulder at $\sim 1460 \mathrm{~cm}^{-1}$ (Figure S6b), such an event is, however, absent in the case of the samples with even $n$ (Figure S6a). A similar effect was reported for the parent lamellar L8- L12 materials. ${ }^{13}$

The FT-IR spectroscopic data were also employed to get insight into the extent and strength of hydrogen bonding in the $\mathrm{C}_{10} \mathrm{C}_{n} \mathrm{C}_{10}$ diurea cross-linked BSs. This sort of information is fundamental to characterize this class of hybrids, since it has been extensively recognized ${ }^{12,13,47}$ that hydrogen bonding interactions between the urea groups play a key role, together with van der Waals interactions between the alkylene chains, in the self-assembly process and ultimately in the structuring of the materials.

Recently, we demonstrated that in L12, all the urea groups present are involved in the formation of an array of strong urea-urea hydrogen-bonded associations that extends throughout the material. ${ }^{15}$ This is not surprising, considering that urea groups are known to produce impressive self-assembly effects (e.g., excellent gelling properties ${ }^{48,49}$ ). This unusual behavior is intimately associated with the particular geometry of the urea moiety. Indeed, the $\mathrm{C}=\mathrm{O}$ group (hydrogen acceptor) of a urea group may form two hydrogen bonds with the pair of $\mathrm{N}-\mathrm{H}$ groups (hydrogen donors) of a neighbor urea group, thus forming highly directional planar bifurcated hydrogen bonds. ${ }^{50}$ For the reasons presented, we decided to inspect the spectral signature of the $\mathrm{C}_{10} \mathrm{C}_{n} \mathrm{C}_{10}$ silsesquioxanes in the "amide I" $\left(1700-1600 \mathrm{~cm}^{-1}\right)$ and "amide II" $\left(1600-1500 \mathrm{~cm}^{-1}\right)$ regions of the FT-IR spectra. ${ }^{51-53}$

The "amide I" and "amide II" modes correspond to the amide I and amide II modes of amides. ${ }^{50}$ The amide I mode receives a major contribution from the $\mathrm{C}=\mathrm{O}$ stretching vibration and is sensitive to the specificity and magnitude of hydrogen bonding. Usually, the amide I band is manifested as a broad envelope 


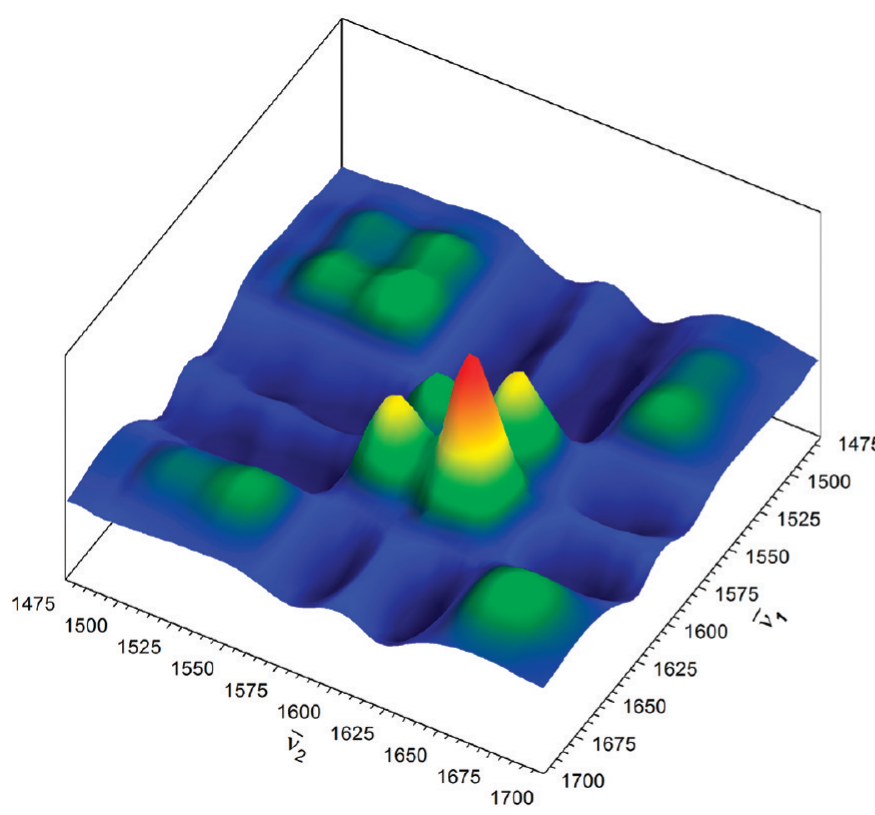

a

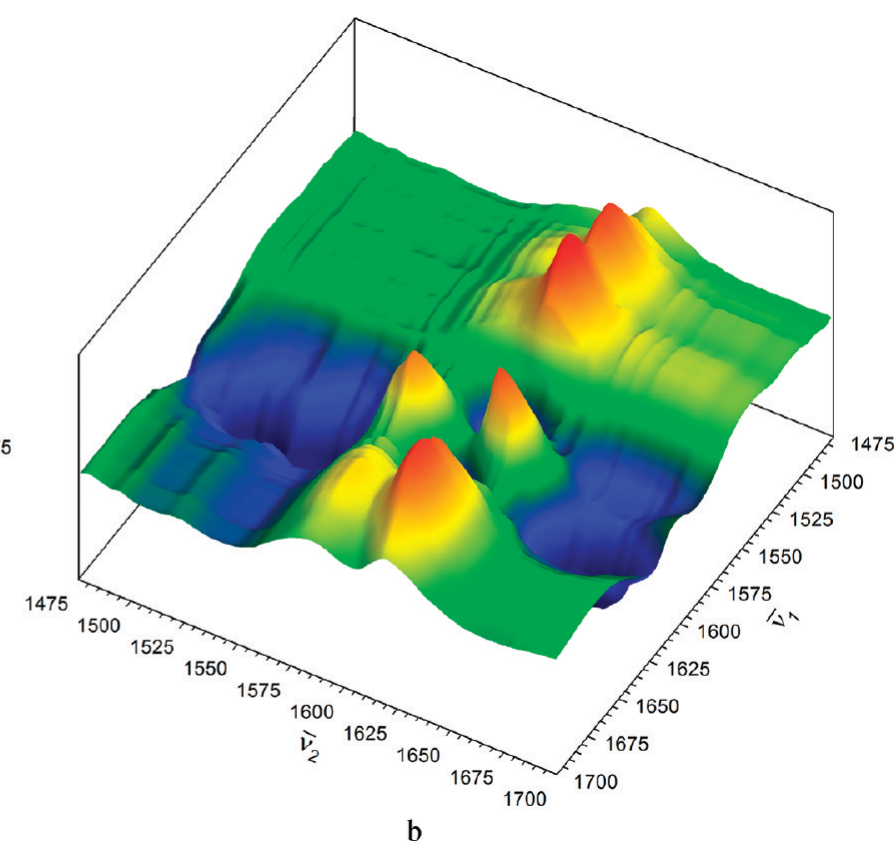

b

Figure 6. Full view of the pseudo-3D stacked trace representation of the synchronous (a) and asynchronous (b) 2D FT-IR correlation spectra of the $\mathrm{C}_{10} \mathrm{C}_{n} \mathrm{C}_{10}$ bridged silsesquioxanes in the $1700-1475 \mathrm{~cm}^{-1}$ region.

composed of several components that represent different $\mathrm{C}=\mathrm{O}$ environments (aggregates). The lower their wavenumber, the stronger the corresponding hydrogen bonds will be. The amide II mode contains a major contribution from the $\mathrm{N}-\mathrm{H}$ in-plane bending vibration. It is sensitive to chain conformation and intermolecular hydrogen bonding, providing rich information about the distribution of hydrogen bond strengths. ${ }^{51}$ Amide II components with higher wavenumbers are correlated with stronger hydrogen bonds.

Because curve-fitting of the "amide I" and "amide II" bands of the $\mathrm{C}_{10} \mathrm{C}_{n} \mathrm{C}_{10}$ hybrids was not straightforward due to the breadth of the band envelopes and the presence of multiple overlapped components (Figure S7), we decided to employ 2D correlation spectroscopic analysis. ${ }^{26}$ This approach has been successfully used by many authors to elucidate hydrogen bonding interactions in various sorts of systems. ${ }^{27,54-58}$ Figures 8 and 9 show the contour map representations of the synchronous and asynchronous $2 \mathrm{D}$ correlation spectra, respectively, of the $\mathrm{C}_{10} \mathrm{C}_{n} \mathrm{C}_{10}$ hybrids in the spectral region between 1700 and $1475 \mathrm{~cm}^{-1}$. The corresponding pseudo-3D stacked trace representations are reproduced in Figure $6 \mathrm{a}$ and $\mathrm{b}$, respectively. The spectral coordinates of the synchronous autopeaks and the spectral coordinates and signs of the synchronous cross-peaks are listed in Table 1. The spectral coordinates of the asynchronous crosspeaks and the order of events are listed in Table 2. Prior to discussing the 2D FT-IR results of the $\mathrm{C}_{10} \mathrm{C}_{n} \mathrm{C}_{10} \mathrm{BSs}$, it is fundamental to mention that the "amide I" band of the related L12 material was decomposed into three components situated at 1668,1645 , and $1624 \mathrm{~cm}^{-1}$, assigned to the absorption of $\mathrm{C}=\mathrm{O}$ groups included in ordered hydrogenbonded urea-urea aggregates of increasing strength. ${ }^{15}$ Henceforth, these aggregates will be designated as aggregates I, II, and III, respectively

The synchronous map of the $\mathrm{C}_{10} \mathrm{C}_{n} \mathrm{C}_{10}$ samples is dominated by a very strong autopeak, $\mathrm{A} 4\left(1620 \mathrm{~cm}^{-1}, 1620 \mathrm{~cm}^{-1}\right.$ ) (Figures $6 \mathrm{a}$ and 8 ), associated with an "amide I" vibration mode, demonstrating

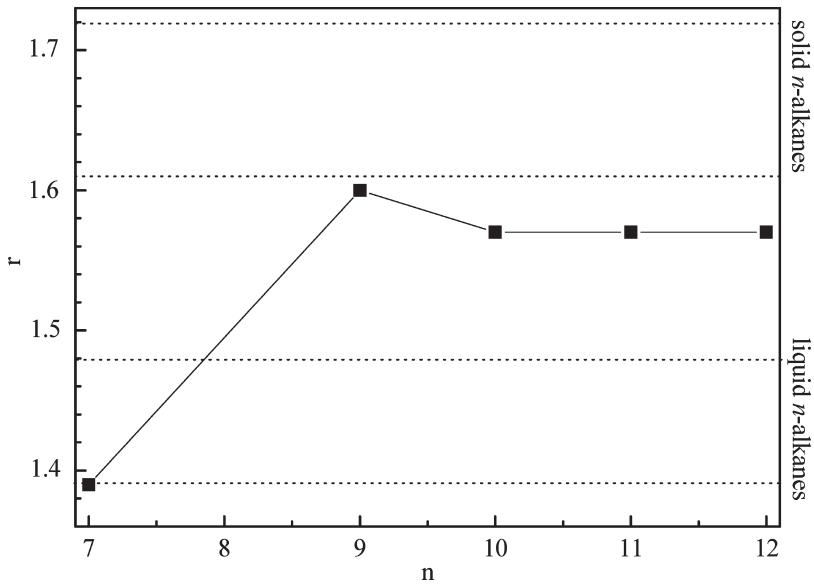

Figure 7. Dependence of the ratio $r$ (with $r=2885 \mathrm{~cm}^{-1} / 2850 \mathrm{~cm}^{-1}$ ) with the length of the central spacer $S_{1}$ in the $C_{10} C_{n} C_{10}$ bridged silsesquioxanes.

that highly ordered and very strong hydrogen-bonded aggregates III $^{15}$ are rapidly formed as a consequence of the incorporation of an increasing number of methylene groups into the alkylene chain of the central spacer, $S_{1}$. A strong autopeak, A3, also develops at coordinates $\left(1583,1583 \mathrm{~cm}^{-1}\right.$ ) (Figures $6 \mathrm{a}$ and 8 and Table 1), clearly pointing out that this "amide II" band undergoes prominent changes under the same chemical perturbation.

Autopeaks A4 and A3 are strongly correlated, as demonstrated by the high correlation intensity levels exhibited by the corresponding cross-peaks B2 $\left(1620,1583 \mathrm{~cm}^{-1}\right.$ ) and B2' (1583, $1620 \mathrm{~cm}^{-1}$ ) (Figures 6a and 8). Their positive signs indicate that the intensity variation (vide intensity increase) of the bands at 1620 and $1583 \mathrm{~cm}^{-1}$ induced by the increase in the length of the central spacer $S_{1}$ takes place in the same direction. The set of autopeaks A1 $\left(1506,1506 \mathrm{~cm}^{-1}\right), \mathrm{A} 2\left(1541,1541 \mathrm{~cm}^{-1}\right)$, and A5 $\left(1668,1668 \mathrm{~cm}^{-1}\right)$ are considerably weaker than autopeaks A4 and A3 (Figures 6a and 8 and Table 1). 


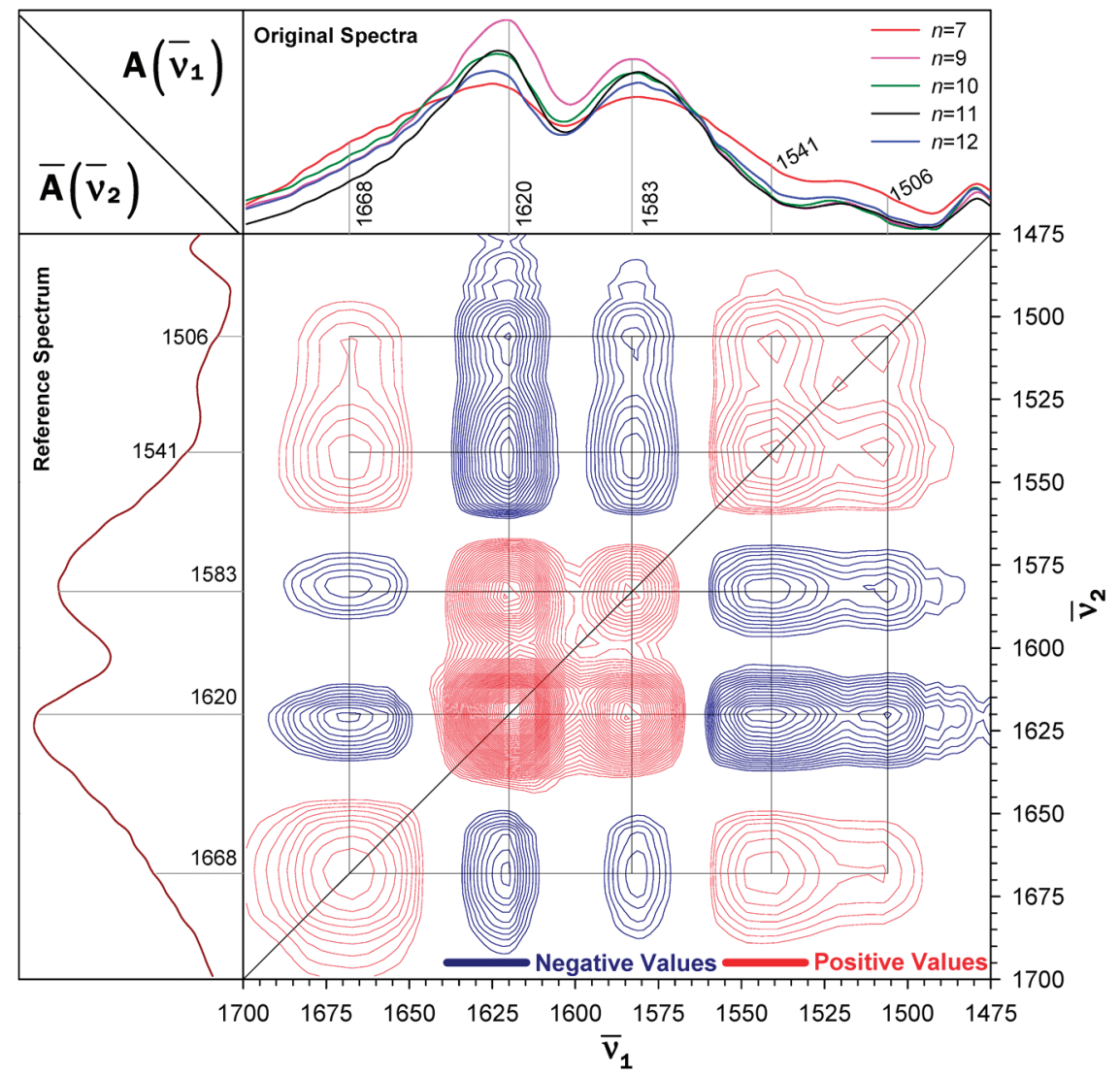

Figure 8. Contour map of the synchronous $2 \mathrm{D}$ FT-IR correlation spectra of the $\mathrm{C}_{10} \mathrm{C}_{n} \mathrm{C}_{10}$ bridged silsesquioxanes in the $1780-1480 \mathrm{~cm}{ }^{-1}$ region.

It is noteworthy that the weakest autopeak A1 is synchronously correlated with the strongest one (i.e., A4), giving rise to the emergence of two relatively intense negative cross-peaks $\mathrm{C} 3$ $\left(1620,1506 \mathrm{~cm}^{-1}\right)$ and $\mathrm{C}^{\prime}\left(1506,1620 \mathrm{~cm}^{-1}\right)$. The situation is still more marked in the case of the synchronously correlated autopeaks A2 and A4, which lead to a pair of even stronger negative cross-peaks, $\mathrm{C} 4\left(1620,1541 \mathrm{~cm}^{-1}\right)$ and $\mathrm{C}^{\prime}(1541$, $1620 \mathrm{~cm}^{-1}$ ).

These results allow inferring that the intensity increase in the 1620 and $1583 \mathrm{~cm}^{-1}$ bands is accompanied by the decrease in the intensity of the 1541 and $1506 \mathrm{~cm}^{-1}$ "amide II" features. The intensity growth of the $1583 \mathrm{~cm}^{-1}$ band at the expense of the intensity decrease in the other two "amide II" events at 1541 and $1506 \mathrm{~cm}^{-1}$ is consistent with the formation of stronger hydrogen bonds. ${ }^{52,53}$

The sign of the pairs of cross-peaks C5 $\left(1668,1583 \mathrm{~cm}^{-1}\right) /$ $\mathrm{C5}^{\prime}\left(1583,1668 \mathrm{~cm}^{-1}\right), \mathrm{C} 6\left(1668,1620 \mathrm{~cm}^{-1}\right) / \mathrm{C6}^{\prime}(1620$, $\left.1668 \mathrm{~cm}^{-1}\right)$ and B3 $\left(1668,1506 \mathrm{~cm}^{-1}\right) / \mathrm{B}^{\prime}\left(1506,1668 \mathrm{~cm}^{-1}\right)$ represents additional evidence of this claim. The negative signs of $\mathrm{C} 5 / \mathrm{C5}^{\prime}$ and $\mathrm{C} 6 / \mathrm{C}^{\prime}$ indicate that an intensity decrease in the $1668 \mathrm{~cm}^{-1}$ "amide I" band, related to the weakest hydrogenbonded aggregates $I^{15}$ results in the central spacer $S_{1}$ becomes longer. This conclusion is, in turn, in perfect agreement with the positive sign of the cross-peak B3/B3', which points out that an intensity reduction of the $1506 \mathrm{~cm}^{-1}$ "amide II" band, ascribed to the weakest hydrogen bonds found in the samples examined, occurs in parallel.

The resolution enhancement provided by asynchronous $2 \mathrm{D}$ correlation spectra and its ability to discriminate overlapped bands is evident in the asynchronous $2 \mathrm{D}$ contour map of the $\mathrm{C}_{10} \mathrm{C}_{n} \mathrm{C}_{10}$ $\mathrm{BSs}$ reproduced in Figures $6 \mathrm{~b}$ and 9. The generated contour map exhibits three intense positive cross-peaks, $\mathrm{S} 1\left(1506,1620 \mathrm{~cm}^{-1}\right)$, S2 $\left(1541,1620 \mathrm{~cm}^{-1}\right)$, and S5 $\left(1609,1620 \mathrm{~cm}^{-1}\right)$, and three intense negative cross-peaks, S3 $\left(1583,1668 \mathrm{~cm}^{-1}\right), \mathrm{S} 4(1583$, $\left.1609 \mathrm{~cm}^{-1}\right)$, and S6 (1620,1668 $\mathrm{cm}^{-1}$ ) (Table 2). This plot reveals interesting facts. Two bands, not detected in the synchronous 2D contour map (Figures $6 \mathrm{a}$ and 8 and Table 1) are now evident at 1616 and $1609 \mathrm{~cm}^{-1}$ (Figures $6 \mathrm{~b}$ and 9). In the present discussion, we will assume that the former band probably corresponds to that located at $1620 \mathrm{~cm}^{-1}$ in the synchronous $2 \mathrm{D}$ contour map. Furthermore, we will consider that the band at $1609 \mathrm{~cm}^{-1}$ is very likely a band masked by the strong band centered at $1620 \mathrm{~cm}^{-1}$. Indeed, close analysis of the "amide I" band profile shown in Figure S7 allows detecting a shoulder in the raw spectra. This event will be associated with the occurrence of a hydrogen-bonded urea-urea aggregate stronger than aggregate III. This new aggregate will be identified as aggregate IV. These results may be interpreted as an indication that the "amide I" and "amide II" regions may be resolved into six components located at $\sim 1668,1620,1609,1583,1541$, and $1506 \mathrm{~cm}^{-1}$. Considering the signs of the cross-peaks that develop in the synchronous and asynchronous contour maps and on the basis of Noda's rule, ${ }^{28,29}$ two major conclusions regarding the sequential order of events that take place in the $\mathrm{C}_{10} \mathrm{C}_{n} \mathrm{C}_{10}$ bridged silsesquioxanes as the number of methylene groups of the central spacer $S_{1}$ is increased may be drawn (Table 2): (1) the formation of aggregate IV $\left(1609 \mathrm{~cm}^{-1}\right)$ precedes that of aggregate III $\left(1620 \mathrm{~cm}^{-1}\right)$, and (2) aggregate III is formed prior to aggregate I $\left(1668 \mathrm{~cm}^{-1}\right)$.

In an attempt to elucidate the relationship between the photoluminescence features and the length of the side spacers 


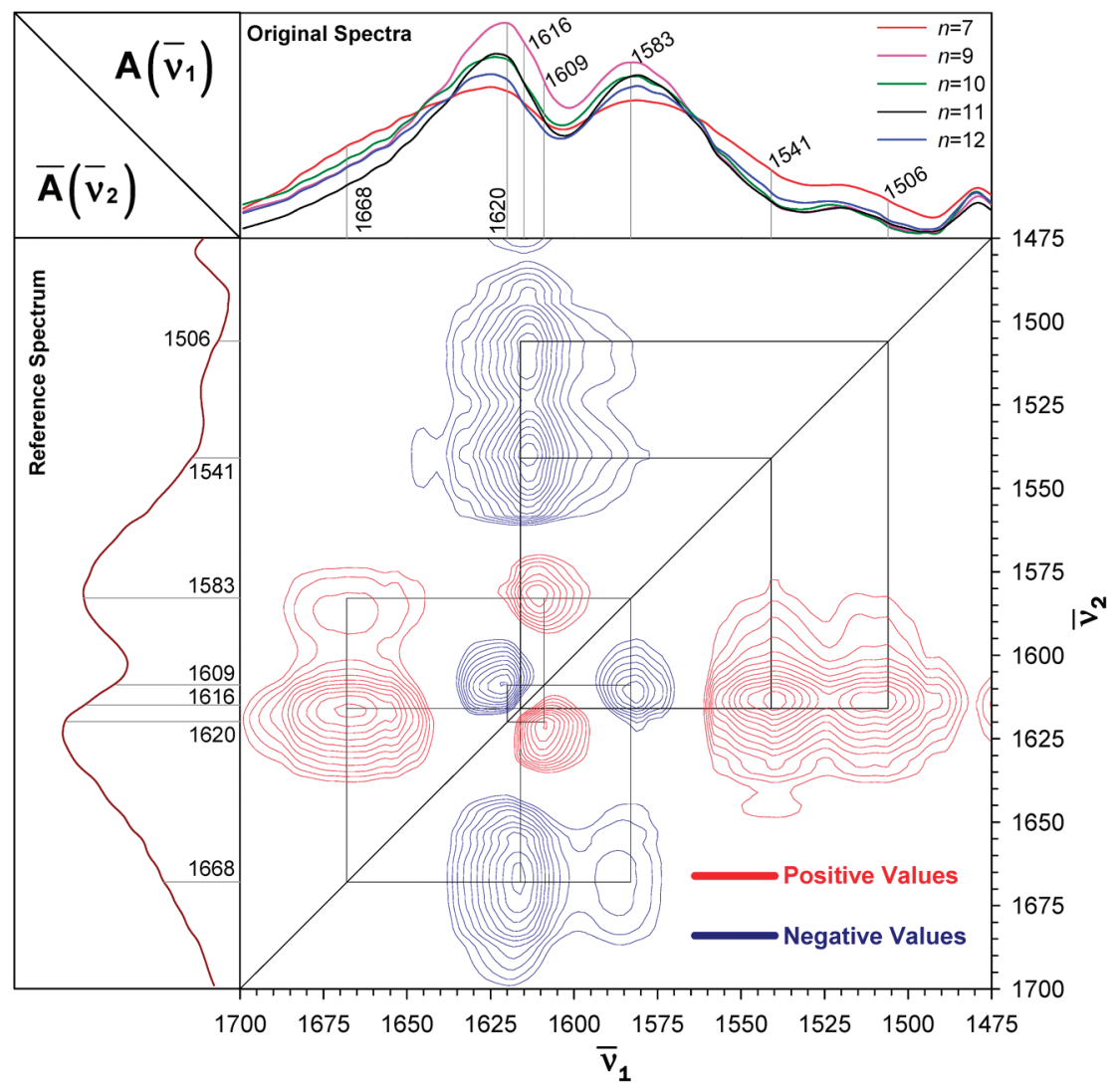

Figure 9. Contour map of the asynchronous 2D FT-IR correlation spectra of the $\mathrm{C}_{10} \mathrm{C}_{n} \mathrm{C}_{10}$ bridged silsesquioxanes in the $1780-1480 \mathrm{~cm}{ }^{-1}$ region.

Table 1. Coordinates of the Synchronous Auto-Peaks and Coordinates and Signs of the Synchronous Cross-Peaks of the "Amide $\mathrm{I}$ " and "Amide II" Regions of the $\mathrm{C}_{10} \mathrm{C}_{n} \mathrm{C}_{10}$ Bridged Silsesquioxanes ${ }^{a}$

\begin{tabular}{ccc} 
& \multicolumn{2}{c}{ synchronous peaks $\Phi\left(\bar{v}_{1}, \bar{v}_{2}\right)$} \\
\hline & & cross-peaks $\left(\bar{v}_{1} \neq \bar{v}_{2}\right)$ \\
\cline { 2 - 3 } autopeaks $\left(\bar{v}_{1}=\bar{v}_{2}\right)$ & positive & negative \\
A1 $(1506,1506)$ & $\mathrm{B} 1(1541,1506) / \mathrm{B}^{\prime}(1506,1541)$ & $\mathrm{C} 1(1583,1506) / \mathrm{C} 1^{\prime}(1506,1583)$ \\
A2 $(1541,1541)$ & $\mathrm{B} 2(1620,1583) / \mathrm{B}^{\prime}(1583,1620)$ & $\mathrm{C} 3(1620,1506) / \mathrm{C} 3^{\prime}(1506,1620)$ \\
A3 $(1583,1583)$ & $\mathrm{B} 3(1668,1541) / \mathrm{B}^{\prime}(1541,1668)$ & $\mathrm{C} 4(1620,1541) / \mathrm{C} 4^{\prime}(1541,1620)$ \\
A4 $(1620,1620)$ & $\mathrm{B} 4(1668,1506) / \mathrm{B}^{\prime}(1506,1668)$ & $\mathrm{C} 5(1668,1583) / \mathrm{C} 5^{\prime}(1583,1668)$ \\
A5 $(1668,1668)$ & & $\mathrm{C} 6(1668,1620) / \mathrm{C} 6^{\prime}(1620,1668)$
\end{tabular}

${ }^{a}$ Wavenumbers in $\mathrm{cm}^{-1}$. Ten synchronous correlation squares can be constructed by linking (1) auto-peaks A1 and A2 with the positive cross-peaks B1 and $\mathrm{B1}^{\prime}$; (2) auto-peaks $\mathrm{A} 1$ and $\mathrm{A} 3$ with the negative cross-peaks $\mathrm{C} 1$ and $\mathrm{Cl}^{\prime}$; (3) auto-peaks $\mathrm{A} 1$ and $\mathrm{A} 4$ with the negative cross-peaks $\mathrm{C} 3$ and $\mathrm{C} 3^{\prime}$; (4) auto-peaks A2 and A3 with the negative cross-peaks C2 and $\mathrm{C}^{\prime}$; (5) auto-peaks A1 and A5 with the positive cross-peaks B4 and B4'; (6) auto-peaks $\mathrm{A} 2$ and $\mathrm{A} 4$ with the negative cross-peaks $\mathrm{C} 4$ and $\mathrm{C}^{\prime}{ }^{\prime}$; (7) auto-peaks A2 and A5 with the positive cross-peaks B3 and B3 ${ }^{\prime}$; (8) auto-peaks A3 and A4 with the positive cross-peaks B2 and B2'; (9) auto-peaks A3 and A5 with the negative cross-peaks C5 and C $5^{\prime}$; (10) auto-peaks A4 and A5 with the negative cross-peaks $\mathrm{C} 6$ and $\mathrm{C} 6{ }^{\prime}$. The positive signs of the cross-peaks $\mathrm{B} i(i=1-4)$ indicate that the intensity variations of the two peaks at $\bar{v}_{1}$ and $\bar{v}_{2}$ induced by the increase of the length of the central spacer $S_{1}$ take place in the same direction. In contrast, the negative sign of the cross-peaks $\mathrm{Cj}(j=1-6)$ under the same chemical perturbation indicate that the intensity variations of the two peaks at $\bar{v}_{1}$ and $\bar{v}_{2}$ change in opposite directions. These data allow concluding that there is a synchronous correlation between (1) the $1506 \mathrm{~cm}^{-1}$ "amide II" band and the 1542 and $1583 \mathrm{~cm}^{-1}$ "amide II" bands and also with the 1668 and $1621 \mathrm{~cm}^{-1}$ "amide I" bands; (2) the "amide II" band at $1542 \mathrm{~cm}^{-1}$ and the "amide II" band at $1583 \mathrm{~cm}^{-1}$ and the "amide I" bands at 1621 and $1669 \mathrm{~cm}^{-1}$; (3) the "amide II" band at $1583 \mathrm{~cm}^{-1}$ and the "amide I" bands at 1621 and $1669 \mathrm{~cm}^{-1}$.

in alkylene-based BSs, we decided to examine the emission and excitation spectra of the $\mathrm{C}_{10} \mathrm{C}_{n} \mathrm{C}_{10}$ materials.

Figure 10 shows the emission spectra under UV excitation recorded for a selected sample, the amorphous $\mathrm{C}_{10} \mathrm{C}_{7} \mathrm{C}_{10}$ hybrid.
The spectra are formed of a large Gaussian-shaped broad band between 320 and $520 \mathrm{~nm}$. Increasing the excitation wavelength from 280 to $320 \mathrm{~nm}$ induces an increase in the relative intensity of the high wavelength side of the spectra. The emission features 
Table 2. Coordinates and Signs of Asynchronous CrossPeaks of the "Amide I" and "Amide II" Regions of the $\mathrm{C}_{10} \mathrm{C}_{n} \mathrm{C}_{10}$ Bridged Silsesquioxanes and Order of Events ${ }^{a}$

\begin{tabular}{cccc} 
& \multicolumn{3}{c}{ sign } \\
\cline { 2 - 3 } asynchronous & \multicolumn{3}{c}{} \\
cross-peak $\psi\left(\bar{v}_{1}, \bar{v}_{2}\right)$ & synchronous $\Phi$ & asynchronous $\psi$ & order of events \\
S1 $(1506,1620)$ & - & + & $1620 \rightarrow 1506$ \\
S2 $(1541,1620)$ & - & + & $1620 \rightarrow 1541$ \\
S3 $(1583,1668)$ & - & - & $1583 \rightarrow 1668$ \\
S4 $(1583,1609)$ & + & - & $1609 \rightarrow 1583$ \\
S5 $(1609,1620)$ & + & + & $1609 \rightarrow 1620$ \\
S6 $(1620,1668)$ & - & - & $1620 \rightarrow 1668$
\end{tabular}

${ }^{a}$ Wavenumbers in $\mathrm{cm}^{-1} ; \rightarrow$ means "before". The sequential order of the events will be $1609 \rightarrow 1620 \rightarrow 1668 \mathrm{~cm}^{-1} ; 1620 \rightarrow 1506 \mathrm{~cm}^{-1} ; 1620 \rightarrow$ $1541 \mathrm{~cm}^{-1} ; 1583 \rightarrow 1668 \mathrm{~cm}^{-1}$.

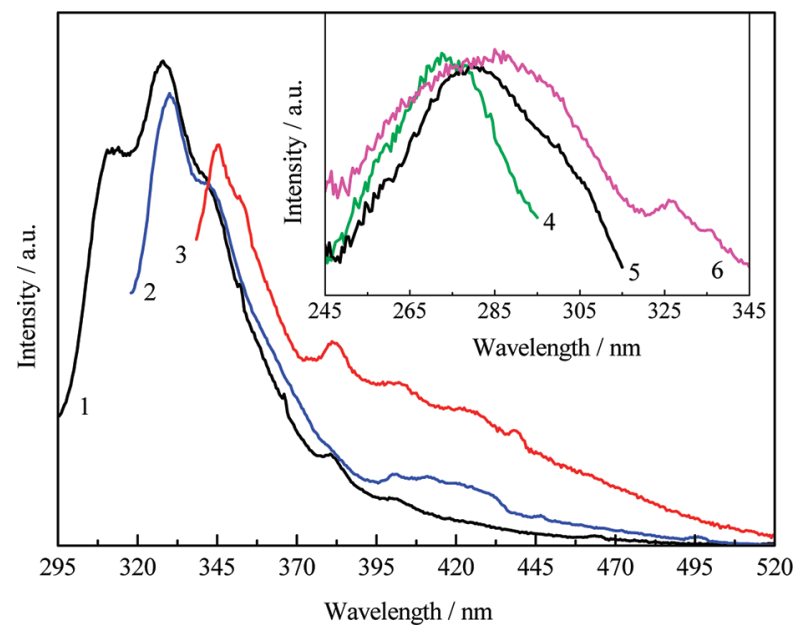

Figure 10. Room temperature emission spectra excited at (1) 280, (2) 300 , and (3) $320 \mathrm{~nm}$ for the $\mathrm{C}_{10} \mathrm{C}_{7} \mathrm{C}_{10}$ bridged silsesquioxane. The inset shows the room temperature excitation spectra monitored at (4) 312 , (5) 330, and (6) $360 \mathrm{~nm}$.

are almost independent of the length of the central alkylene spacer $S_{1}(n=7,9-12)$ (Figure S8). Interestingly, these spectra are very similar to those reported for the P12-derived $\mathbf{A 1 2}{ }^{16}$ hybrid (inset of Figure S8), despite not only the longer side spacers $\mathrm{S}_{2}$ of $\mathrm{C}_{10} \mathrm{C}_{n} \mathrm{C}_{10}$ BS but also the different synthetic conditions used. Similar emission features were also observed and extensively detailed for amorphous analogous hybrids incorporating propylene-based side spacers, such as the diureasils, ${ }^{59,60}$ the diurethanesils, ${ }^{61}$ and the mono- ${ }^{62}$ and di- $^{63}$ amidosils, being ascribed to the overlap of two distinct emissions mediated by donor-acceptor pair transitions that occur within the urea, urethane, or amide cross-linkages, respectively, and within the siliceous skeleton due to the presence of oxygen-related defects. ${ }^{59,60}$

These two emission components were clearly identified through time-resolved spectroscopy. Figure 11 shows the emission spectra of $\mathrm{C}_{10} \mathrm{C}_{11} \mathrm{C}_{10}$ acquired for distinct starting delay (SD) values under $365 \mathrm{~nm}$ excitation wavelength. For SD values smaller than $5.00 \mathrm{~ms}$, the spectra unambiguously display two bands around 427 (marked with an arrow in Figure 11) and $500 \mathrm{~nm}$, previously ascribed to electron-hole recombination occurring in the siliceous domains and in the urea cross-linkages,

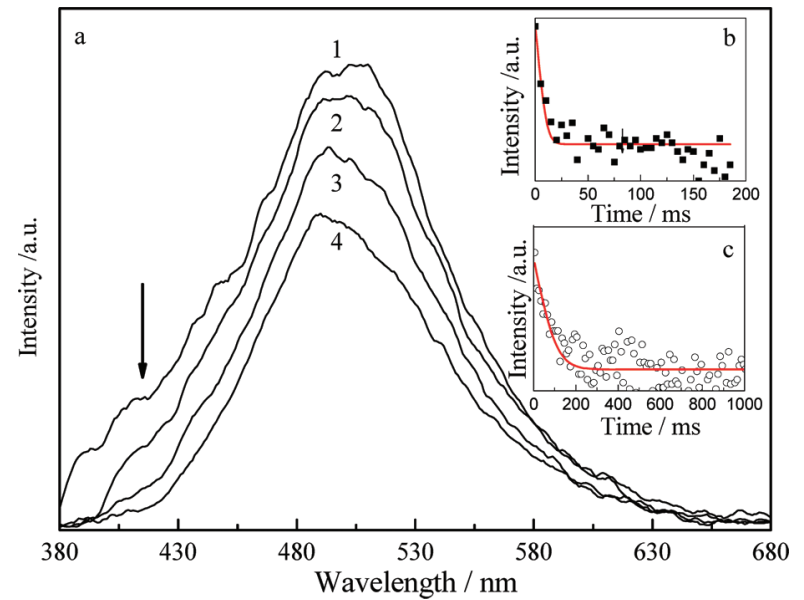

Figure 11. (a) Low-temperature (12 K) time-resolved emission spectra of the $\mathrm{C}_{10} \mathrm{C}_{11} \mathrm{C}_{10}$ bridged silsesquioxane excited at $365 \mathrm{~nm}$ acquired under different starting delay values: (1) 0.05, (2) 1.00, (3) 5.00, and (4) $20.00 \mathrm{~ms}$. The integration window was $20.00 \mathrm{~ms}$. Emission decay curves monitored at (b) 427 and (c) $505 \mathrm{~nm}$ excited at $365 \mathrm{~nm}$; the solid lines represent the data best fit using a single exponential function.

respectively. ${ }^{59,60}$ At higher SD values, only the long-lived urea-related component could be observed. To detail the time scale behind each component, lifetime measurements were performed by monitoring the emission decay curves at 427 and $500 \mathrm{~nm}$. Both decay curves are modeled by a single exponential function, yielding lifetime values of $3.4 \pm 0.2$ and $42.7 \pm 4.0 \mathrm{~ms}$ for the siliceous and urea-related components, respectively.

Although the lifetime value of the siliceous-related component resembles that acquired for the diureasils, the urea-related lifetime value is substantially smaller $(3.5 \pm 0.2$ and $160.0 \pm 8.0 \mathrm{~ms}$, respectively $\left.{ }^{59}\right)$. Energy transfer between these two distinct emitting centers was quantitatively estimated for the diureasil host with the smallest number of polymer repeat units $(\mathrm{d}-\mathrm{U}(600))$ yielding rate values of $1.3 \times 10^{9} \mathrm{~s}^{-1}$ (dipole-dipole mechanism) and $3.7 \times 10^{8} \mathrm{~s}^{-1}$ (exchange process). ${ }^{64}$ Because these energy transfer rates strongly depend on the distance between the two emitting centers, the similar lifetimes of the siliceous-related component in the long-chain analogue $\mathrm{d}-\mathrm{U}(2000)$ and $\mathrm{C}_{10} \mathrm{C}_{11} \mathrm{C}_{10}$ suggest a similar average distance between the siliceous domains and the urea cross-links, indicating that the side spacers in $\mathrm{C}_{10} \mathrm{C}_{11} \mathrm{C}_{10}$ most probably adopt gauche conformations. Furthermore, the 4-fold increase of the radiative transition decay rate (inverse of the lifetime at $10 \mathrm{~K})$ in $\mathrm{C}_{10} \mathrm{C}_{11} \mathrm{C}_{10}$ relative to $\mathrm{d}-\mathrm{U}(2000)$ is probably associated with the increasing vibronic-spin-orbit interaction ${ }^{64}$ due to a distinct distribution of hydrogen bonds induced by the increase in the length of the side spacers. The latter result proves that the emission features of the urea-related component of diurea-cross-linked BSs are sensitive to the length of the side spacers (we recall that there are only three methylene groups in the side spacers of the diureasils versus 10 methylene groups in those of the $\mathrm{C}_{10} \mathrm{C}_{n} \mathrm{C}_{10}$ hybrids).

The typical excitation spectra monitored within the emission band in Figure 10 shows a broad band peaking at $280 \mathrm{~nm}$, whose peak position and full-width-at-half-maximum (fwhm) deviates toward the red as the monitoring wavelength increases (inset in Figure 10). Similarly to the situation found for the emission data, these excitation spectra are identical to those monitored for the $\mathbf{A 1 2}^{16}$ hybrid. The high- and low-energy side were attributed 
to the preferential excitation of the siliceous- and urea-related emission ${ }^{59,60}$ Apart from an increase in the relative intensity of the high-wavelength side of the emission spectra, those acquired at $12 \mathrm{~K}$ (Figure S9) resemble those measured at room temperature (Figure 10).

The absolute emission quantum yield was acquired under the excitation wavelength that maximizes the emission features (i.e., $280 \mathrm{~nm})$. For higher excitation wavelengths $(330-350 \mathrm{~nm})$ the quantum yield values are below 0.01 . The quantum yield values are poorly affected by changes in the alkylene chain lengths, being $0.07 \pm 0.01$ and $0.06 \pm 0.01$ for the $\mathrm{C}_{10} \mathrm{C}_{n} \mathrm{C}_{10}$ samples with $n=7$ and 11 , respectively. These are considerably smaller than those reported for the P12-derived hybrids, namely, the lamellar L12, and for the amorphous A12 with quantum yield values of $0.14 \pm$ $0.01^{15}$ and $0.24 \pm 0.02,{ }^{16}$ respectively, both excited at $290 \mathrm{~nm}$. The latter was the maximum value measured for this type of material. Nevertheless, it should be noted that the photoluminescence measurements and the quantum yield values of A12 are time-dependent. Upon aging at ambient atmosphere, the quantum yield value decreased $\sim 2.5$ times. The photoluminescence data and quantum yield values reported here for the $\mathrm{C}_{10} \mathrm{C}_{n} \mathrm{C}_{10}$ $\mathrm{BSs}$ do not show any variation in the same period of time. We should also emphasize that the above-mentioned quantum yield values resemble the maximum values measured for diureasil hybrids $(0.07-0.09 \pm 0.01)$ under longer excitation wavelengths $(360-400 \mathrm{~nm}) .^{59}$

\section{- CONCLUSIONS}

In the present work, a novel series of hybrids, represented by the notation $\mathrm{C}_{10} \mathrm{C}_{n} \mathrm{C}_{10}$, were prepared from silsesquioxane precursors, including decylene chains as side spacers and alkylene chains containing $7,9,10,11$, or 12 methylene groups as the central spacer. The main goal of the present study was to evaluate the influence of the length of the side spacers on the morphology and structure of alkylene-based BS hybrid materials.

The SEM images provided evidence that the morphology the $\mathrm{C}_{10} \mathrm{C}_{n} \mathrm{C}_{10}$ samples, ranging from irregular micro-objects to dense spheroidal microparticles, clearly differs from the platelet-like morphology of the L8-12 samples, ${ }^{10-17}$ but resembles closely that of the L12D material. ${ }^{17}$ In particular, the characteristic L12D microsphere-like morphology mimicking sea sponges, in which thin, folded films assemble along an edge-to-face fashion, was especially recognized in $\mathrm{C}_{10} \mathrm{C}_{9} \mathrm{C}_{10}$. Taking into account that the same synthetic procedure ( $\mathrm{HCl}$-catalyzed hydrolytic route in the presence of a large volume of DMSO) was employed to produce $\mathrm{L} 12 \mathrm{D}$ and the $\mathrm{C}_{10} \mathrm{C}_{n} \mathrm{C}_{10}$ hybrids, we believe that the morphological similarity found is a consequence of solvent polarity effects. ${ }^{17}$

The lamellar structure of all the $\mathrm{C}_{10} \mathrm{C}_{n} \mathrm{C}_{10}$ samples investigated was evidenced by XRD and SAXS. The lamellae are arranged along a structure composed of 2D siliceous domains separated by nonperpendicularly oriented alkylene chains containing variable amounts of trans and gauche conformers. SAXS, ${ }^{13} \mathrm{C}$ CP/MAS NMR, FT-IR, and FT-Raman spectroscopic data demonstrated that, although the alkylene chains of the side and central spacers of $\mathrm{C}_{10} \mathrm{C}_{7} \mathrm{C}_{10}$ are completely disordered, in samples with a longer central spacer, $S_{1}$, the proportion of fully stretched and densely packed alkylene chains (all-trans conformers) is enhanced significantly. The highest degree of order and tightest packing are attained for $n=9$. This structuring trend contrasts markedly with that observed in the case of the $\mathrm{Ln}$ family ${ }^{14}$ for which the degree of order increases with an increase in the number of methylene groups in the central spacer, provided that at least eight methylene groups are present in the alkylene chains.

For the first time, a 2D correlation FT-IR spectroscopic analysis has been performed on the "amide I" and "amide II" bands of $\mathrm{BS}$ hybrids, such as the $\mathrm{C}_{10} \mathrm{C}_{n} \mathrm{C}_{10}$ materials. It allowed us to conclude that the replacement of the side propylene chains by decylene chains deeply influenced the strength and extent of the urea-urea hydrogen-bonded array. New highly ordered hydrogen-bonded aggregates (so-called aggregates IV), stronger than those found in $\mathbf{L} 12^{15}$ (aggregates I, II and III), are formed. Moreover, in the $\mathrm{C}_{10} \mathrm{C}_{n} \mathrm{C}_{10}$ series, no aggregates II were detected. ${ }^{15}$ The formation of aggregates IV occurs prior to that of aggregates III. Aggregates I are formed last.

The emission spectra of selected $\mathrm{C}_{10} \mathrm{C}_{n} \mathrm{C}_{10}$ samples are practically independent of the length of the central alkylene spacer and similar to those reported for hybrid materials containing propylene side spacers, such as the nonstructured BS A12, ${ }^{16}$ the diureasils, ${ }^{59,60}$ the diurethanesils, ${ }^{61}$ the diamidosils, ${ }^{63}$ and the structured lamellar bilayer monoamidosils. ${ }^{62}$ The emission is ascribed to the overlap of two distinct components that occur within the urea, urethane, and amide cross-linkages in the case of the diureasils, diurethanesils, and amidosils, respectively, and within the siliceous nanodomains. Time-resolved spectroscopic data has enabled us to demonstrate for the first time that the emission features of the urea-related component of the emission of diurea cross-linked BSs depend critically on the length of the alkylene-based side spacers. It also allowed us to infer that the average distance between the siliceous regions and the urea crosslinks is practically the same in BSs, including propylene- and decylene-based side chains, suggesting that the longer chains adopt gauche conformations.

The excitation spectra of the $\mathrm{C}_{10} \mathrm{C}_{n} \mathrm{C}_{10}$ hybrids resemble that of A12. ${ }^{16}$ However, although the lifetime value of the siliceousrelated component resembles that acquired for the diureasils, the urea-related lifetime value is substantially smaller, providing evidence of the crucial role played by the longer side spacers on the dynamics of the two distinct emissions.

The absolute emission quantum yield of $\mathrm{C}_{10} \mathrm{C}_{11} \mathrm{C}_{10}$ is considerably smaller than the highest value reported for the P12-derived materials (A12), but, unlike the latter BS, it is time-independent.

\section{ASSOCIATED CONTENT}

S Supporting Information. Figures $\mathrm{S} 1-\mathrm{S} 9$ and Table S1. Figure S1: Silicon environments of the $\mathrm{C}_{10} \mathrm{C}_{n} \mathrm{C}_{10}$ bridged silsesquioxanes. Figure S2: Carbon indexation of the $\mathrm{C}_{10} \mathrm{C}_{n} \mathrm{C}_{10}$ bridged silsesquioxanes. Figure S3: Representative cross-section of the AFM profile of the $\mathrm{C}_{10} \mathrm{C}_{10} \mathrm{C}_{10}$ bridged silsesquioxane. Figure S4: Birefringence of the $\mathrm{C}_{10} \mathrm{C}_{10} \mathrm{C}_{10}$ bridged silsesquioxane. Figure S5: FT-Raman $v \mathrm{CH}_{2}$ region of the $\mathrm{C}_{10} \mathrm{C}_{n} \mathrm{C}_{10}$ bridged silsesquioxanes. Figure S6: FT-IR $\delta \mathrm{CH}_{2}$ region of the $\mathrm{C}_{10} \mathrm{C}_{n} \mathrm{C}_{10}$ bridged silsesquioxanes. Figure S7: "Amide I" and "amide II" regions of the $\mathrm{C}_{10} \mathrm{C}_{n} \mathrm{C}_{10}$ bridged silsesquioxanes. Figure S8: Emission spectra $(300 \mathrm{~K})$ of the $\mathrm{C}_{10} \mathrm{C}_{n} \mathrm{C}_{10}$ bridged silsesquioxanes (excited at $280 \mathrm{~nm}$ ). Figure S9: Emission spectra $(12 \mathrm{~K})$ of the $\mathrm{C}_{10} \mathrm{C}_{n} \mathrm{C}_{10}$ bridged silsesquioxanes (excited at 280 and $360 \mathrm{~nm}$ ). Table S1: Carbon indexation and silicon environments of the $\mathrm{C}_{10} \mathrm{C}_{n} \mathrm{C}_{10}$ bridged silsesquioxanes. This material is available free of charge via the Internet at http://pubs.acs.org. 


\section{AUTHOR INFORMATION}

\section{Corresponding Author}

*(V.d.Z.B.) Phone: +351 259 350253. Fax: +351 259350480 . E-mail: vbermude@utad.pt. (M.W.C.M.) Phone: +33 467147219. Fax: +33 467147 212. E-mail:michel.wong-chi-man@enscm.fr.

\section{Present Addresses}

${ }^{\nabla}$ CEA-LITEN/DTNM/LCSN, 17 rue des Martyrs, F 38054 Grenoble, Cedex 9, France

'State Key Laboratory of Chemical Resource Engineering, Beijing University of Chemical Technology, 15 Beisanhuan Donglu, Beijing 100029, China.

\section{ACKNOWLEDGMENT}

This work was financially supported by the Fundação para a Ciência e a Tecnologia (FCT)/Ministère des Affaires Etrangères et Européennes (Programme Pessoa/Hubert Curien, Contract 441.00 2009/2010) and CNRS. M. Fernandes thanks FCT for a grant (SFRH/BD/38530/2007) and University Montpellier 2 for financial support. LNLS is thanked for providing beamtime at the SAXS beamline and for financial support. The authors are grateful to Professor Isao Noda (The Proctor and Gamble Company, Cincinnati, OH, USA) for enlightening discussions regarding the 2D FT-IR data and acknowledge Andreia G. Macedo for the AFM measurements.

\section{REFERENCES}

(1) Corriu, R. J. P.; Moreau, J. J. E.; Thépot, P.; Wong Chi Man, M. Chem. Mater. 1992, 4, 1217-1224.

(2) Shea, K. J.; Loy, D. A.; Webster, O. J. Am. Chem. Soc. 1992, $114,6700-6710$.

(3) Loy, D. A.; Shea, K. J. Chem. Rev. 1995, 95, 1431-1442.

(4) Nobre, S. S.; Cattoën, X.; Ferreira, R. A. S.; Wong Chi Man, M.; Carlos, L. D. Phys. Status Solidi RRL 2010, 4, 55-57.

(5) Carlos, L. D.; Ferreira, R. A. S.; de Zea Bermudez, V.; Ribeiro, S. J. L. Adv. Mater. 2009, 21, 509-534.

(6) Zamboulis, A.; Moitra, N.; Moreau, J. J. E.; Cattoën, X.; Wong Chi Man, M. J. Mater. Chem. 2010, 20, 9322-9338.

(7) Hatton, B. D.; Landskron, K.; Whitnall, W.; Perovic, D. D.; Ozin, G. A. Adv. Funct. Mater. 2005, 15, 823-829.

(8) Fujita, S.; Inagaki, S. Chem. Mater. 2008, 20, 891-908.

(9) Boury, B.; Corriu, R. J. P. Chem. Commun. 2002, 8, 795-802.

(10) Moreau, J. J. E.; Vellutini, L.; Wong Chi Man, M.; Bied, C.; Bantignies, J. L.; Dieudonné, P.; Sauvajol, J. L. J. Am. Chem. Soc. 2001, 123, 7957-7958.

(11) Moreau, J. J. E.; Pichon, B. P.; Wong Chi Man, M.; Bied, C.; Pritzkow, H.; Bantignies, J. L.; Dieudonné, P.; Sauvajol, J. L. Angew. Chem., Int. Ed. 2004, 43, 203-206.

(12) Moreau, J. J. E.; Vellutini, L.; Wong Chi Man, M.; Bied, C.; Dieudonné, P.; Bantignies, J. L.; Sauvajol, J. L. Chem.—Eur. J. 2005, 11, 1527-1537.

(13) Bantignies, J. L.; Vellutini, L.; Maurin, D.; Hermet, P.; Dieudonné, P.; Wong Chi Man, M.; Bartlett, J. R.; Bied, C.; Sauvajol, J. L.; Moreau, J. J. E. J. Phys. Chem. B 2006, 110, 15797-15802.

(14) Moreau, J. J. E.; Vellutini, L.; Dieudonné, P.; Wong Chi Man, M.; Bantignies, J. L.; Sauvajol, J. L.; Bied, C. J. Mater. Chem. 2005, $15,4943-4948$.

(15) Nobre, S. S.; Brites, C. D. S.; Ferreira, R. A. S.; de Zea Bermudez, V.; Carcel, C.; Moreau, J. J. E.; Rocha, J.; Wong Chi Man, M.; Carlos, L. D. J. Mater. Chem. 2008, 18, 4172-4182.

(16) Nobre, S. S.; Cattoën, X.; Ferreira, R. A. S.; Carcel, C.; de Zea Bermudez, V.; Wong Chi Man, M.; Carlos, L. D. Chem. Mater. 2010, 22, 3599-3609.
(17) Fernandes, M.; Cattoën, X.; Wong Chi Man, M.; de Zea Bermudez, V. Cryst. Eng. Commun. 2011, 13, 1410-1415.

(18) Moreau, J.J. E.; Vellutini, L.; Wong Chi Man, M.; Bied, C. J. Am. Chem. Soc. 2001, 123, 1509-1510.

(19) Moreau, J. J. E.; Vellutini, L.; Wong Chi Man, M.; Bied, C. Chem.-Eur. J. 2003, 9, 1594-1599.

(20) Bied, C.; Moreau, J. J. E.; Vellutini, L.; Wong Chi Man, M. J. Sol-Gel Sci. Technol. 2003, 26, 583-586.

(21) Xu, Q. H.; Moreau, J. J. E.; Wong Chi Man, M. J. Sol-Gel Sci. Technol. 2004, 32, 111-115.

(22) Moreau, J. J. E.; Pichon, B.; Bied, C.; Wong Chi Man, M. J. Mater. Chem. 2005, 15, 3929-3936.

(23) Joly, P.; Ardes-Guisot, N.; Kar, S.; Granier, M.; Durand, J. O.; Melnyk, O. Eur. J. Org. Chem. 2005, 2473-2480.

(24) Horcas, I.; Fernandez, R.; Gomez-Rodriguez, J. M.; Colchero, J.; Gomez-Herrero, J.; Baro, A. M. Rev. Sci. Instrum. 2007, 78, 013705$1-013705-8$.

(25) PeakFit 4; AISN Software Inc.: Jandel Scientific Software, 2591 Rerner Boulevard, San Rafael, CA 94901, USA, 1995.

(26) Noda, I.; Ozaki, Y. in Two-Dimensional Correlation Spectroscopy-Applications in Vibrational and Optical Spectroscopy; John Wiley \& Sons, Ltd.: Chichester, UK, 2004.

(27) Noda, I.; Liu, Y. L.; Ozaki, Y. J. Phys. Chem. 1996, 100, 8665-8673.

(28) Noda, I.; Dowrey, A. E.; Marcott, C.; Story, G. M.; Ozaki, Y Appl. Spectrosc. 2000, 54, 236A-248A.

(29) Noda, I. Appl. Spectrosc. 2000, 54, 994-999.

(30) Noda, I. Appl. Spectrosc. 1993, 47, 1329-1336.

(31) Noda, I. Appl. Spectrosc. 1990, 44, 550-561.

(32) Noda, I. J. Am. Chem. Soc. 1989, 111, 8116-8118.

(33) Tailor-made code was developed by author Sousa, J. M., 2009.

(34) Hikosaka, M. Y.; Pulcinelli, S. H.; Dahmouche, C. V. S. K.; Craievich, A. F. J. Non-Cryst. Solids 2006, 352, 3705-3710.

(35) Klug, H. P.; Alexander, L. E. X-ray Diffraction Procedures; Wiley: New York, 1974.

(36) Clauss, J.; Pulcinelli, S. H. Macromolecules 1992, 25, 5208-5214.

(37) Parikh, A. N.; Schivley, M. A.; Koo, E.; Seshadri, K.; Aurentz,

D.; Mueller, K.; Allara, D. L J. Am. Chem. Soc. 1997, 119, 3135-3143.

(38) Wang, L. Q.; Liu, J.; Exarhos, G. J.; Flanigan, K. Y.; Bordia, R. J. Phys. Chem. B 2000, 104, 2810-2816.

(39) Brown, K. G.; Bicknellbrown, E.; Ladjadj, M. J. Phys. Chem. 1987, 91, 3436-3442.

(40) Venkataraman, N. V. Phys. Chem. Chem. Phys. 2002, 4, 4533-4538.

(41) Venkataraman, N. V; Vasudevan, S. J. Phys. Chem. B 2001, 105, 7639-7650.

(42) Wang, R. W.; Baran, G.; Wunder, S. L. Langmuir 2000, 16, 6298-6305.

(43) Snyder, R. G.; Strauss, H. L.; Elliger, C. A. J. Phys. Chem. 1982, $86,5145-5150$

(44) Vaia, R. A.; Teukolsky, R. K.; Giannelis, E. P. Chem. Mater. 1994, 6, 1017-1022.

(45) Hagemann, H.; Strauss, H. L.; Snyder, R. G. Macromolecules 1987, 20, 2810-2819.

(46) Zerbi, G.; Del Topp, M. In Modern Polymer Spectroscopy; Zerbi, G., Ed.; Wiley-VCH: Weinheim, 1999.

(47) Bantignies, J. L.; Vellutini, L.; Sauvajol, J. L.; Maurin, D.; Wong Chi Man, M.; Dieudonné, P.; Moreau, J. J. E. J. Non-Cryst. Solids 2004, 345, 605-609.

(48) de Loos, M.; van Esch, J.; Stokroos, I.; Kellogg, R. M.; Feringa, B. L. J. Am. Chem. Soc. 1997, 119, 12675-12676.

(49) van Esch, J.; Kellogg, R. M.; Feringa, B. L. Tetrahedron Lett. 1997, 38, 281-284.

(50) Born, L.; Hespe, H. Colloid Polym. Sci. 1985, 263, 335-341.

(51) Miyazawa, T.; Shimanouchi, T.; Mizushima, S. I. J. Chem. Phys. 1956, 24, 408-418.

(52) Skrovanek, D. J.; Howe, S. E.; Painter, P. C.; Coleman, M. M. Macromolecules 1985, 18, 1676-1683.

(53) Coleman, M. M.; Lee, K. H.; Skrovanek, D. J.; Painter, P. C. Macromolecules 1986, 19, 2149-2157. 
(54) Czarnecki, M. A.; Ozaki, Y. Phys. Chem. Chem. Phys. 1999, 797-800.

(55) Sun, B.; Lin, Y.; Wu, P.; Siesler, H. W Macromolecules 2008, $41,1512-1520$.

(56) Isawa, K.; Ogasawara, T.; Masuda, H.; Okabayashi, H.; O’Connor, C. J.; Noda, I. Colloid Polym. Sci. 2002, 280, 380-388.

(57) Zhang, J; Tsuji, H.; Noda, I.; Ozaki, Y. J. Phys. Chem. B 2004, 108, 11514-11520.

(58) Noda, I.; Liu, Y. L.; Ozaki, Y. J. Phys. Chem. 1996, 100, 8674-8680.

(59) Carlos, L. D; Ferreira, R. A. S.; de Zea Bermudez, V.; Ribeiro, S. J. L. Adv. Funct. Mater 2001, 11, 111-115.

(60) Carlos, L. D.; Ferreira, R. A. S.; Pereira, R. N.; Assunção, M.; de Zea Bermudez J. Phys. Chem. B 2004, 108, 14924-14932.

(61) Gonçalves, M. C.; de Zea Bermudez, V.; Ferreira, R. A. S.; Carlos, L. D.; Ostrovskii, D.; Rocha, J. Chem. Mater. 2004, 60, 2530-2543.

(62) Nunes, S. C.; Planelles-Aragó, J.; Sá Ferreira, R.; Carlos, L. D.; de Zea Bermudez, V. Chem.-Eur. J. 2010, 18, 2688-2699.

(63) Nunes, S. C.; de Zea Bermudez, V.; Cybinnska, J.; Sá Ferreira, R. A.; Carlos, L.; Legendziewicz, J.; Silva, M. M.; Smith, M. J.; Ostrovskii, D. J. Alloys Compd. 2008, 451, 510-515.

(64) Nobre, S. S.; Lima, P. P.; Mafra, L.; Ferreira, R. A. S.; Freire, R. O.; Fu, L.; de Zea Bermudez, V.; Malta, O. L.; Carlos, L. D. J. Phys. Chem. C 2007, 111, 3275-3284. 